OPEN ACCESS

Edited by:

Frank John Spera,

University of California, Santa Barbara,

United States

Reviewed by:

Henry J. B. Dick,

Woods Hole Oceanographic

Institution, United States

Michael Perfit,

University of Florida, United States

Jon Blundy,

University of Bristol, United Kingdom

*Correspondence:

Marine Boulanger

marineb@crpg.cnrs-nancy.fr

Specialty section:

This article was submitted to

Petrology,

a section of the journal

Frontiers in Earth Science

Received: 22 April 2020

Accepted: 21 August 2020

Published: 15 September 2020

Citation:

Boulanger M, France L, Deans J. R. L.,

Ferrando C, Lissenberg C. J. and

von der Handt $A$ (2020).

Front. Earth Sci. 8:554598.

doi: 10.3389/feart.2020.554598

\section{Magma Reservoir Formation and Evolution at a Slow-Spreading Center (Atlantis Bank, Southwest Indian Ridge)}

\author{
Marine Boulanger ${ }^{1 *}$, Lydéric France ${ }^{1}$, Jeremy R.L. Deans ${ }^{2}$, Carlotta Ferrando ${ }^{1,3}$, \\ C. Johan Lissenberg ${ }^{4}$ and Anette von der Handt ${ }^{5}$
}

${ }^{1}$ Université de Lorraine, CNRS, CRPG, Nancy, France, ${ }^{2}$ School of Biological, Environmental, and Earth Sciences, University of Southern Mississippi, Hattiesburg, MS, United States, ${ }^{3}$ Dipartimento di Scienze Della Terra, Università Degli Studi di Pavia, Pavia, Italy, ${ }^{4}$ School of Earth and Ocean Sciences, Cardiff University, Cardiff, United Kingdom, ${ }^{5}$ Department of Earth Sciences, University of Minnesota, Minneapolis, MN, United States

Several ODP-IODP expeditions drilled oceanic core complexes interpreted as exhumed portions of lower crust close to the ridge axis, and provide the community with invaluable sampling opportunity for further constraining magmatic processes involved in the formation of the slow-spreading lower oceanic crust. ODP Hole 735B presents the most primitive lithologies sampled at Atlantis Bank oceanic core complex (Southwest Indian Ridge) in a $\sim 250 \mathrm{~m}$ thick section that was previously interpreted as a single crustal intrusion. We combined detailed structural and petrographic constraints with whole rock and in situ mineral analyses of this section in order to precisely determine the processes of emplacement, crystallization, and melt migration within the lower crust. The lower half of the unit is comprised of alternating olivine gabbros and troctolites showing intrusive contacts, magmatic fabrics, and crystal-plastic fabrics. Such structures and primitive lithologies are lacking in the upper half, rather uniform, gabbroic sequence. Whole rock compositions highlight the cumulative character of both lower and upper units and a great compositional variability in the lower sequence, whereas the upper sequence is homogeneous and differentiates up-section. In situ analyses of mineral phases document magma emplacement processes and provide evidence for ubiquitous reactive porous flow (RPF) during differentiation. We show that the whole section, and related geochemical unit, constitutes a single magmatic reservoir, in which the lower unit is formed by stacked primitive sills formed by repeated recharge of primitive melts and melt-present deformation. Recharge led to partial assimilation of the crystallizing primitive cumulates, and hybridization with their interstitial melts. Hybrid melts were progressively collected in the overlying mushy part of the reservoir (upper unit), whereas the sills' residual hybrid melts differentiated by RPF processes under a predominantly crystallization regime. Similarly, hybrid melts' evolution in the upper unit was governed by upward RPF, and progressive differentiation and accumulation of evolved melts at the top of the reservoir. Our results provide the community with the first integrated model for magma reservoir formation in the lower slow-spreading oceanic crust that can potentially be applied to other magmatic lower crust sections. 
Keywords: Atlantis Bank, lower oceanic crust, magma intrusion, crystal mush, reactive porous flow, assimilationfractional crystallization

\section{INTRODUCTION}

Slow-spreading ridges represent more than $50 \%$ of the global oceanic ridge system (spreading rates $<40 \mathrm{~mm}$ year $^{-1}$, Dunn, 2015) and are characterized by both heterogeneous crustal structure (e.g., oceanic core complexes or OCCs) and composition. Most of this heterogeneity can be linked to uneven distribution of melt generation within the mantle below the ridge axis (e.g., Tucholke and Lin, 1994; Dunn et al., 2005; Rubin and Sinton, 2007; Dunn, 2015 and references therein). Uneven melt supply results in the formation of intermittent and discontinuous magma reservoirs within the crust (e.g., Dick et al., 2003; Carbotte et al., 2015), contrasted reservoir geometry (axial magma chamber or sill intrusions; Jian et al., 2016; Canales et al., 2017), and variable depth of melt emplacement which can range between 2 and $16 \mathrm{~km}$ depth below seafloor (Dunn et al., 2005; Singh et al., 2006; Canales et al., 2017; Bennett et al., 2019). The common thread running through all processes that potentially govern magma accretion at spreading ridges is the importance of melt migration mechanisms involved. Among them, reactive porous flow (RPF) tend to be considered ubiquitous during the evolution of gabbroic magma reservoirs, since crystal mushes forming porous and permeable frameworks constitute the principal medium of the magma plumbing system (Lissenberg et al., 2019 and references therein).

Long in situ sections of lower slow-spreading oceanic crust have been sampled by deep drilling in OCCs. These structures form during asymmetric spreading at the ridge axis and associated exhumation of both lower oceanic crust and upper mantle (e.g., Dick et al., 1991b; Escartín et al., 2003; Ildefonse et al., 2007). Two drilled holes have reached more than $1,400 \mathrm{mbsf}$ (meters below sea floor), one in the Atlantis Massif OCC on the Mid-Atlantic Ridge (MAR, IODP Hole U1309D), and the other in the Atlantis Bank OCC on the Southwest Indian Ridge (SWIR, ODP Hole 735B). Their study enabled to characterize the modes of magma emplacement and evolution at these locations, but only at a large scale (Dick et al., 2000; John et al., 2004; Grimes et al., 2008; Godard et al., 2009; Dick et al., 2019a). The crust appears highly heterogeneous in both complexes and lacks any systematic downhole variations in modal compositions, or clear lateral continuity as evidenced from multiple drill holes, for example, at Atlantis Bank (Dick et al., 2000; MacLeod et al., 2017; Dick et al., 2019a). Despite the disparities between the ODP Hole 735B and IODP Hole U1309D, similar types of magma emplacement mechanisms have been inferred, which suggests a continuity of processes for the accretion of slow-spreading lower oceanic crust (Blackman et al., 2006; Dick et al., 2019a; Dick et al., 2019b). Whole rock compositions, together with the lack of modal downhole variations, led Godard et al. (2009) to interpret the cumulate sequence sampled in Atlantis Massif as the result of multiple magma intrusions. Upward differentiation trends on $>200 \mathrm{~m}$ thicknesses have been identified in ODP Hole 735B based on whole rock major element compositions (Dick et al., 2000;
Natland and Dick, 2002), and in situ mineral compositions (Dick et al., 2002). These trends are interpreted as the result of cyclic major magmatic events that formed by multiple intrusions and differentiated in situ during large-scale upward percolation of melts (Dick et al., 2000; Dick et al., 2019a). In addition, detailed studies of individual samples collected in drilled cores from Atlantis Massif and Atlantis Bank enabled workers to find evidence for extensive melt-rock or melt-mush reactions (e.g., in olivine-rich troctolites from Hole U1309D, Suhr et al., 2008; Drouin et al., 2009; Ferrando et al., 2018; or in gabbroic samples from Hole 735B, Robinson et al., 2000; Natland and Dick, 2001; Dick et al., 2002; Gao et al., 2007), suggesting that these processes likely play a substantial role in the differentiation of melts in the lower crust (Lissenberg and MacLeod, 2016; Dick et al., 2019a).

Here, we integrate structural, petrographic and highresolution geochemical data of a $\sim 250 \mathrm{~m}$ section from ODP Hole $735 \mathrm{~B}$ characterized as a single intrusion by Dick et al. (2000) and Natland and Dick (2002). We reconstruct the different steps of evolution of this magma reservoir, leading to the first detailed reservoir model for a slow-spreading lower oceanic crust section. We particularly focused on the impact of RPF processes on the reservoir by using modeling and the assimilation-fractional crystallization (AFC) equation of DePaolo (1981). The novelty of our approach here is to consider an entire sample suite interpreted as representative of an entire reservoir for the study of RPF, instead of individual samples as considered in previous studies on the lower (slow-spreading) oceanic crust.

\section{GEOLOGICAL SETTING}

The Atlantis Bank OCC is located on the eastern flank of the Atlantis II Transform Fault $\sim 95 \mathrm{~km}$ south of the ultra-slow SWIR (Dick et al., 1991b-Figure 1). The $\sim 2 \mathrm{~km}$ uplift of lower crust lithologies at Atlantis Bank is the consequence of a $\sim 1 \mathrm{~km}$ flexural uplift due to detachment faulting, exacerbated by transformparallel normal faulting on the eastern flank of the structure. The latter event is linked to a change of spreading direction at the ridge axis between 19.5 and $7.5 \mathrm{Ma}$ (Baines et al., 2003, Baines et al., 2007). The OCC is mainly composed of gabbroic lithologies, bordered to the East by extrusive lithologies (dikes and pillow lavas) and to the West by mantle lithologies affected by variable degrees of serpentinization (Dick et al., 2000; MacLeod et al., 2017; Dick et al., 2019b). The top of the structure is defined by a $4 \mathrm{~km}$-wide and $\sim 8.5 \mathrm{~km}$-long horizontal platform at $\sim 700 \mathrm{~m}$ depth below sea level, in which three deep holes have been drilled by the ODP/IODP consortium (MacLeod et al., 2017).

The deepest and most studied core so far is ODP Hole 735B, which reached a total depth of $1,508 \mathrm{mbsf}$, and recovered $\sim 1,300 \mathrm{~m}$ of gabbroic lithologies. The 735B drilled cores are composed of $68 \%$ olivine gabbros, $23 \%$ oxide and oxidebearing gabbros, in addition to $5 \%$ troctolites and troctolitic gabbros (1.9\% troctolites sensu stricto, Dick et al., 2019a) and $4 \%$ gabbros sensu stricto (MacLeod et al., 2017). Some minor 


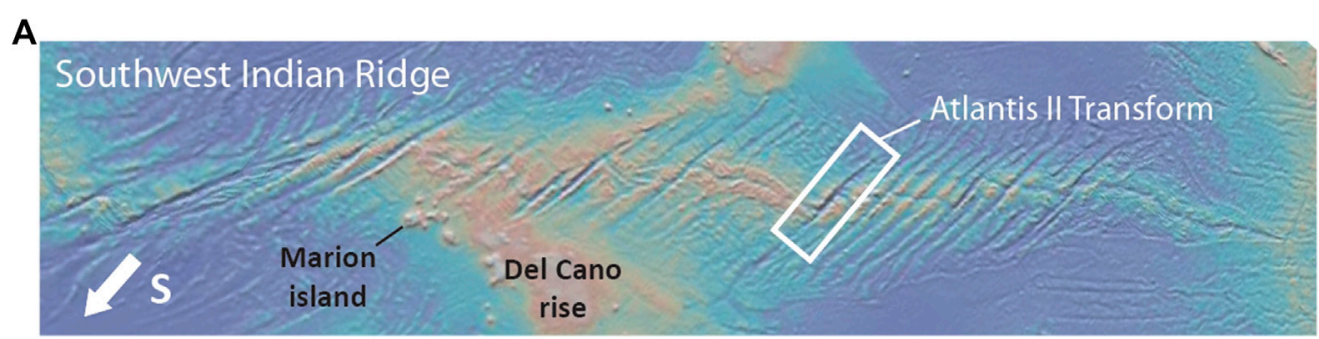

B

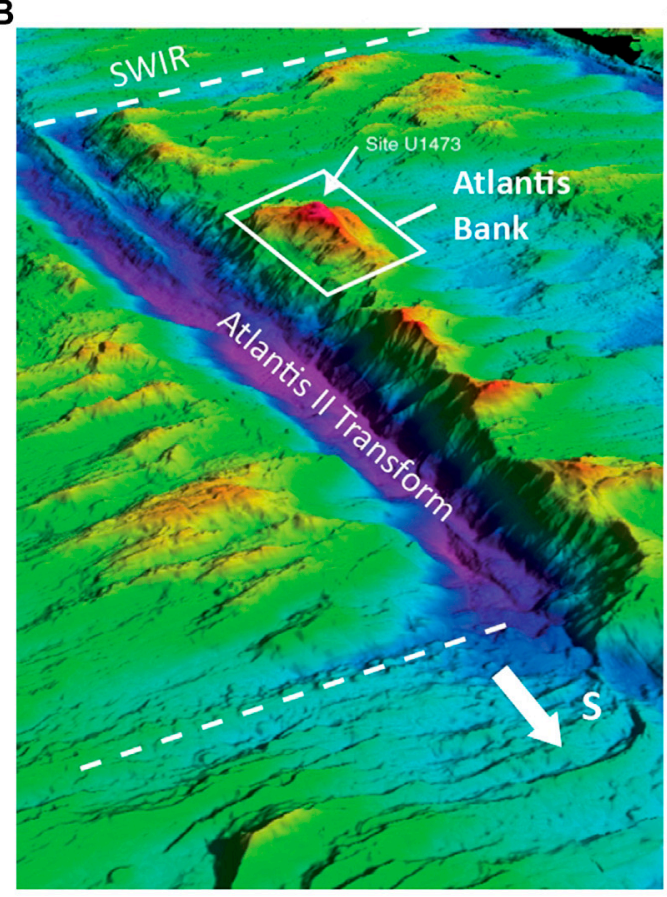

C.

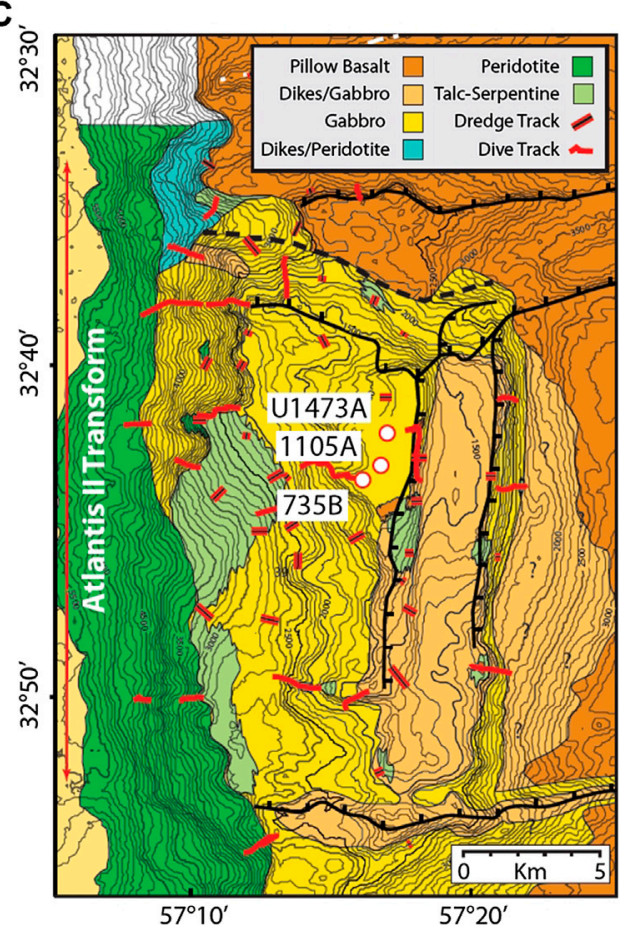

FIGURE 1 | (A) Location map of the Atlantis II Transform on the Southwest Indian Ridge, (B) 3D bathymetric map of the Atlantis II Transform and location of the Atlantis Bank Oceanic Core Complex (IODP Publications), and (C) geological map of the Atlantis Bank oceanic core complex and location of ODP Holes 735B and 1105A, and IODP Hole U1473A (modified from Dick et al., 2019b).

lithologies such as diabase dikes and felsic veins were also recovered (Dick et al., 2000). Whole rock and in situ major element compositions indicate three to five upward differentiation trends (Figure 2). Each trend has been interpreted as the signature of individual intrusions, potentially crosscutting each other, and emplaced during large magmatic events by multiple intrusions (Dick et al., 2000; Dick et al., 2002; Dick et al., 2019a). In this study we focus on the second unit from the top (274-53 mbsf), which contains some of the most primitive lithologies in the hole $(\mathrm{Mg} \#=$ molar ratio $\mathrm{Mg} /$ $\left[\mathrm{Mg}+\mathrm{Fe}_{\mathrm{tot}}\right] \times 100$, of Ti-poor lithologies ranging between 74.5 and 86.8-MacLeod et al., 2017). The selected unit is relatively fresh and one of the least deformed of the drilled section, and presents the entire compositional range of rocks recovered in Hole 735B. U-Pb zircon dates suggest intrusion of the series ranging from 11.974 to $11.926 \mathrm{Ma}$ (Rioux et al., 2016).

The intrusion has been described as two separate units ( $\mathrm{V}$ and VI) during ODP Leg 118 and Leg 176 (Dick et al., 1991a; Dick et al., 2000). The upper unit, Unit $\mathrm{V}$, is a massive $108.3 \mathrm{~m}$-long olivine gabbro unit. The lower unit, Unit VI, is described as a $153.6 \mathrm{~m}$-long "lower compound olivine gabbro," including more than 200 distinct igneous intervals (Dick et al., 2000). In detail, Unit VI is composed of four interleaved subunits of olivine gabbros or troctolites, crosscut by various amounts of "synkinematic" oxide gabbros (Dick et al., 2000). Oxide-rich lithologies are often associated with strain localization (Natland et al., 1991; Dick et al., 2000), and are more common in Unit VI. The intrusion is bordered at the top by a $50.5 \mathrm{~m}$-long massive oxide gabbro unit (Unit IV) and at the bottom by a $63 \mathrm{~m}$-long evolved gabbroic unit (Unit VII).

\section{METHODS}

The structure and textures of Unit V and VI from ODP Hole $735 \mathrm{~B}$ were re-described at the Kochi Core Center, Japan. Igneous 


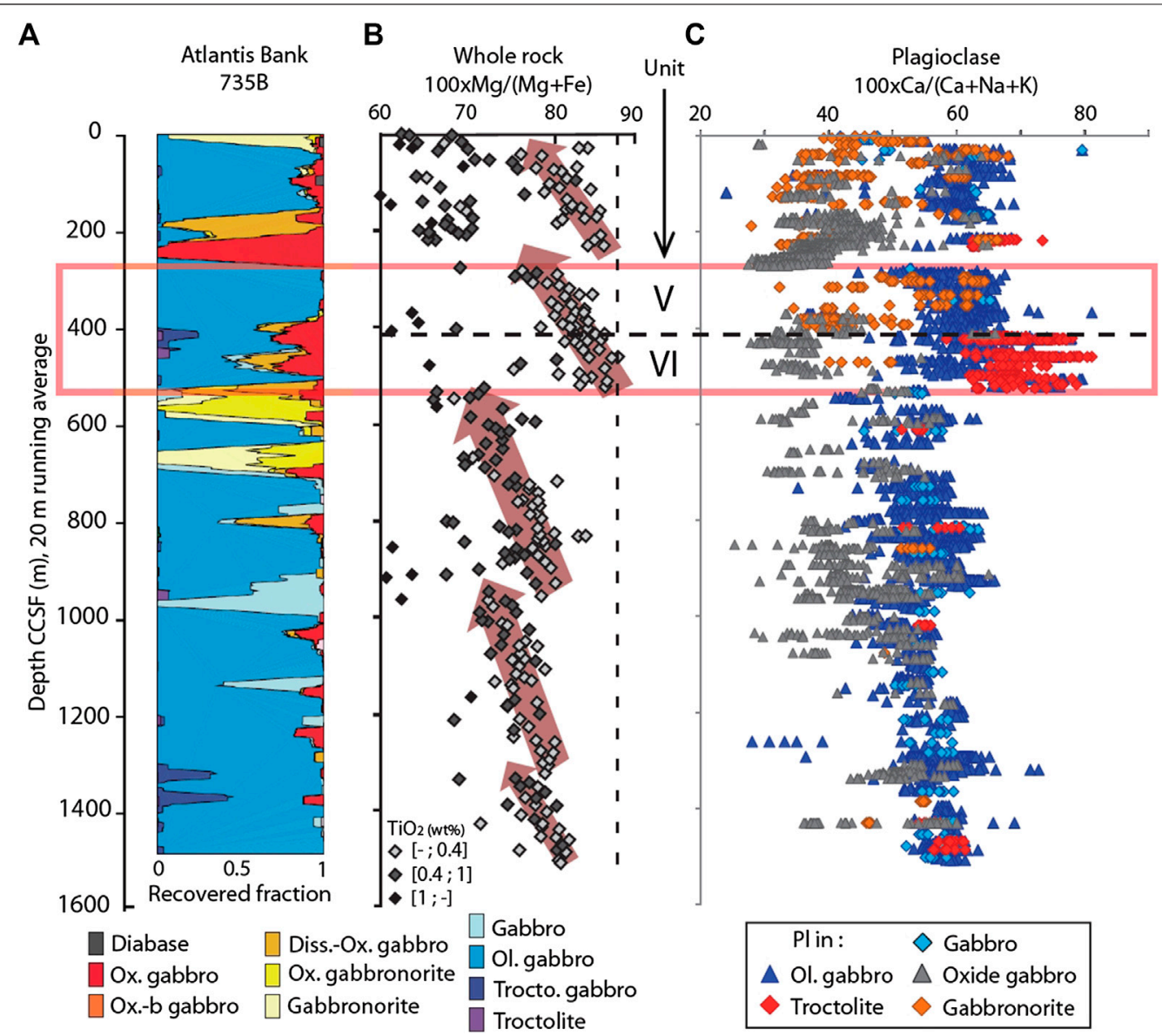

FIGURE 2 | Comparison between (A) the lithostratigraphic variations of Hole 735B with relative abundances averaged over $20 \mathrm{~m}$ (from Macleod et al., 2017 ), (B) the corresponding shipboard X-ray fluorescence (XRF) whole rock gabbro Mg\# trends (modified from Dick et al., 2000), and (C) in situ plagioclase An content (data from Dick et al., 2002).

contacts used here were initially defined and delineated by the Shipboard Scientific Party (Dick et al., 1999), and are defined by changes in mineral proportion and/or grain size; sheared contacts are also observed. Magmatic fabrics are defined by a shape preferred orientation of igneous phases like plagioclase, pyroxene, and/or olivine with no to little internal crystalplastic strain and no recrystallization. Crystal-plastic fabrics are defined by a shape preferred orientation of porphyroclasts and neoblasts with internal crystal-plastic strain. The level of fabric development of each fabric type is based on a qualitative ranking system plotted as a thickness corrected running average developed by the Shipboard Scientific Party (following Dick et al., 1999-Figure 3). Magmatic fabrics range from no alignment, rank of 0 , to almost all phases aligned, rank of 3. Crystal-plastic fabrics range from no alignment, rank of 0 , to porphyroclastic (close to equal proportion of porphyroclasts and neoblasts), rank of 3 , to ultramylonite, rank of 5 .

In total, 95 gabbroic lithologies (characterized as olivine gabbros and troctolites by Dick et al., 1999) were resampled to get representative samples exhibiting the entire range of compositional variation observed in the available whole rock data (Supplementary Table S1; Figure 2). Only rocks characterized as olivine gabbros and troctolites were sampled in order to focus on the early and intermediate stages of the magmatic differentiation. We excluded oxide gabbros also present in the lower $\sim 150 \mathrm{~m}$ of the sequence that are associated with highly differentiated, late-stage melts, as emphasized by MacLeod et al. (2017) and supported by the experimental work of Koepke et al. (2018). In addition, many oxide gabbros present evidence for late emplacement by deformation-assisted intrusion of an oxide-bearing melt in a more primitive gabbroic host in disequilibrium (Koepke et al., 2018 and references therein). We also excluded samples presenting strong crystal-plastic deformation or alteration features that might have disrupted their initial magmatic geochemical signatures. The mineral mode of 50 of the samples was determined by using the ImageJ software on thin section scans (Schneider et al., 2017; http://imagej.nih.gov/ij/).

Major element contents of minerals from 78 samples were quantified by Electron Probe Micro Analyzer at Laboratoire Magmas et Volcans (Clermont-Ferrand, France) and the University of Minnesota (United States). The thin sections 


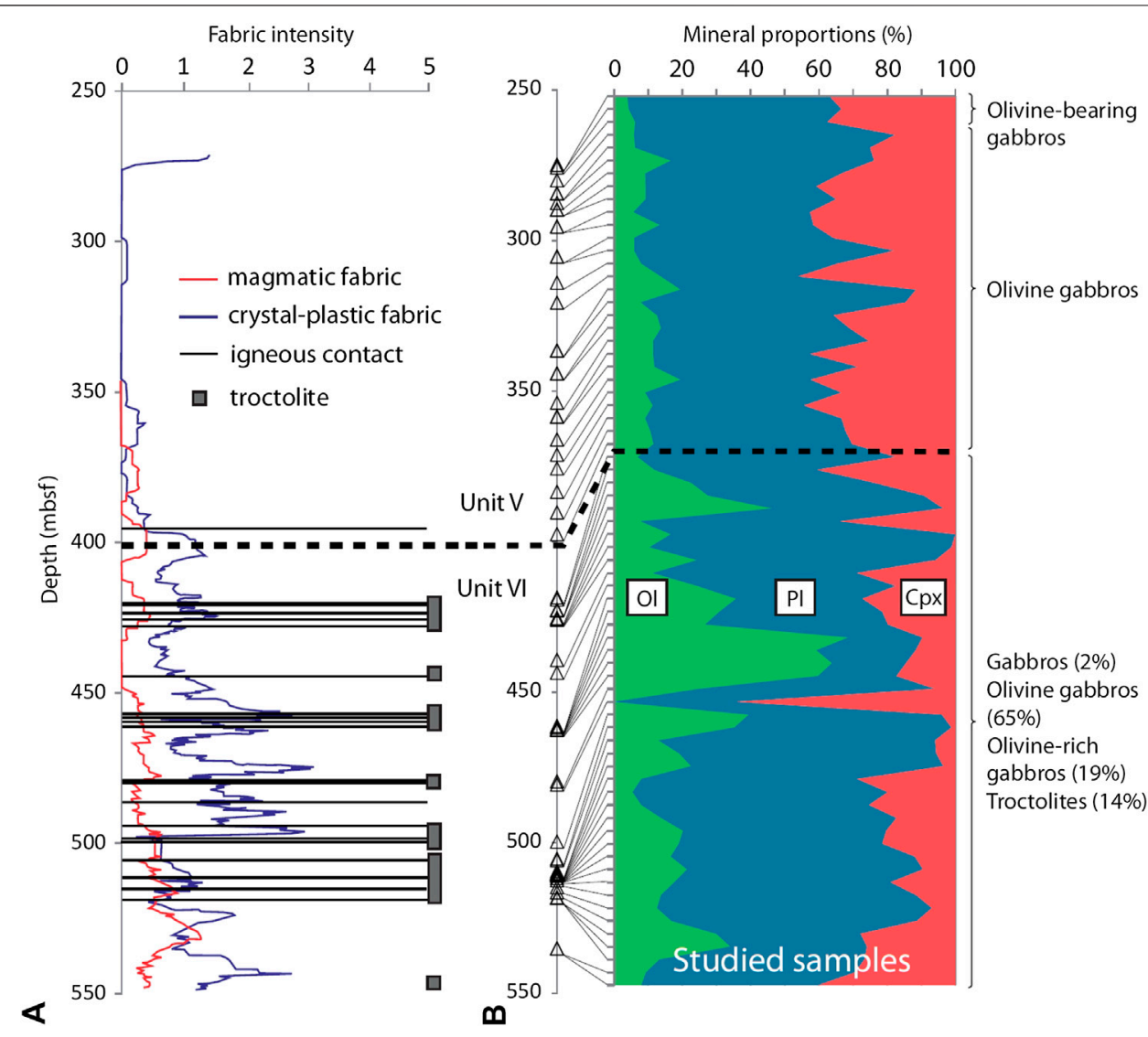

FIGURE 3 | (A) Downhole distribution of fabric intensity for the section studied. Red line is magmatic fabric intensity (0-3); blue line is crystal-plastic fabric intensity (0-5). The fabric intensity is a qualitative scale developed by Shipboard Scientific Party (1999) and the intensity is plotted as a thickness-corrected running average. The horizontal black lines represent igneous contacts (Natland and Dick, 2002; their Table 1). The gray boxes are the location of troctolites. (B) Location at depth of the samples collected in Units V and VI (units' name after Dick et al., 2000) with their corresponding modal compositions. The black dotted line represents the approximate transition between the Lower and the Upper unit.

analyzed were selected according to their lack of alteration or strong crystal plastic deformation, and for sampling at regular intervals of $<5 \mathrm{~m}$ on average between each group of samples. In order to get the entire compositional variability of minerals from the selected samples, when possible at least three grains of the main constituting minerals were analyzed in on average 5 representative areas of the thin section. For each grain, core and rim (geometrical) were analyzed. At Clermont-Ferrand, we used a Cameca SX100 equipped with four wavelength-dispersive $\mathrm{X}$-ray spectrometers. Analyses were performed with a $15 \mathrm{kV}$ accelerating potential and a focused beam using a $15 \mathrm{nA}$ beam current. Counting times were of 10 or $20 \mathrm{sec}$ on peak and also for background. At Minnesota, we used a JEOL JXA-8900 equipped with four wavelength-dispersive X-ray spectrometers. Analyses were performed with a $15 \mathrm{kV}$ accelerating potential, a beam current of $20 \mathrm{nA}$, and beam diameters of $10 \mu \mathrm{m}$ for clinopyroxene, $5 \mu \mathrm{m}$ for plagioclase, and $1 \mu \mathrm{m}$ for olivine. Counting times were of $10 \mathrm{~s}$ on peak and off peak for all elements. The data and associated analytical errors are available in Supplementary Material (see details and calibration standards for each element in Supplementary Table S2).
Mineral trace elements of 24 samples were analyzed in situ with a ThermoFinnigan Element 2 XR inductively coupled plasma mass spectrometer (eXtended Range-ICP-MS) coupled with a laser ablation (LA) system Téledyne G2 at Géosciences Montpellier (AETE-ISO regional facility of the OSU OREME, Montpellier University, France). Where possible, the same analytical strategy as for major element measurements regarding the selection of samples and the location of in situ analyses was followed. Signal acquisition was made in Time Resolved Acquisition, counting $120 \mathrm{sec}$ for the background, and $60 \mathrm{sec}$ for the sample measurement. The frequency of the laser was of $10 \mathrm{~Hz}$, with an energy density of $\sim 6.2 \mathrm{~J} \mathrm{~cm}^{2}$. Ablation experiments were conducted under helium which was mixed with argon before entering the plasma. Clinopyroxenes (Cpx) were analyzed with a laser spot size of $77 \mu \mathrm{m}$, while a spot size of $102 \mu \mathrm{m}$ was used for olivines (Ol) and plagioclases (Pl). Data were processed using the GLITTER software (van Achterbergh et al., 2001). All measured concentrations were calibrated using the synthetic glass NIST 612 with the values of Pearce et al. (1997). The internal standards used for the minerals are ${ }^{43} \mathrm{Ca}$ for $\mathrm{Cpx}$, and ${ }^{29} \mathrm{Si}$ for $\mathrm{Pl}$ and $\mathrm{Ol}$, with the values previously analyzed in the same minerals by Electron Probe Micro Analyzer. An average of 
the values analyzed by LA-ICP-MS for the standard reference basalt BIR-1G is available in Supplementary Table S3, together with all trace elements data and associated errors.

\section{RESULTS}

Although whole rock geochemical trends suggest a first-order relative continuity of compositions (e.g., $\mathrm{Mg \# -Figure} \mathrm{2),} \mathrm{the}$ section can be divided in two distinct units based on structural, lithological, and geochemical criteria. In the following we refer to the Upper unit and to the Lower unit, which together correspond to the ensemble formed by Unit V and Unit VI as described by Dick et al. (2000). We first describe the structural and petrographic variations and then describe the compositional variations in each unit.

\section{Structure and Petrographic Variations}

The Lower unit ( 400-530 mbsf) is heterogeneous and presents numerous igneous contacts recovered at different depths all along the section. Intrusive contacts separate subunits whose thicknesses range from meters to tens of meters. Lithologies range from the more primitive troctolites and olivine-rich gabbros to olivine gabbros and olivine-bearing gabbros (Figure 3B). Oxide gabbros are also present within this unit, and are associated with deformed areas present throughout the interval. The presence of igneous contacts is very frequently associated with the presence of troctolites sensu lato (i.e., Ol-rich lithologies-Figure 3A). Within each subunit defined by the igneous contacts, the transition between lithologies is gradational. The modal proportion of $\mathrm{Ol}$ tends to decrease (from 69 to 4\%) and proportions of Cpx increase (from 1 to $64 \%$ ) toward the top of each subunit. This is especially the case for one subunit located at $\sim 510 \mathrm{mbsf}$ and described in Hole $735 \mathrm{~B}$ cores 90R-2 and 90R-3 (see Supplementary Figure S1). From bottom to top of the subunit, the modal composition of lithologies progressively change from troctolites with $<5 \%$ interstitial Cpx and up to $\sim 25 \% \mathrm{Ol}$, to $\mathrm{Ol}$ gabbros with up to $40 \% \mathrm{Cpx}$ and $<5 \% \mathrm{Ol}$. Samples' textures are subophitic to granular with grain size varying from medium-to coarse-grained. All lithology types may record a crystal-plastic fabric at all intensity ranks, and whose intensity is highly variable with depth (Figure 3A; Supplementary Figure S2). The sampled lithologies representing the primary magmatic background of the sequence show magmatic fabrics whose intensity and orientation vary along the section. A maximum intensity of $\sim 2$ is reached at the bottom of the sequence, at about $530 \mathrm{mbsf}$ (Figure 3A). No clear systematics between the orientation and intensity of the magmatic fabric, and depth can be observed. Common mineral textures in the Lower unit are rounded Ol chadacrysts in poikilitic $\mathrm{Pl}$ or Cpx in troctolites (Figure 4D), $\mathrm{Pl}$ crystals presenting discordant polysynthetic twins on their irregular grain boundaries in poikilitic $\mathrm{Cpx}$ (Figures $4 \mathrm{~A}-\mathrm{C}$ ), and/or Pl crystals with similar irregular grain boundaries and complex optical zoning in $\mathrm{Ol}$ gabbros (green arrows, Figures 4B-D). Such textures have previously been interpreted as evidence for RPF (e.g., Lissenberg and MacLeod, 2016), and are better developed in samples with magmatic fabrics in $\mathrm{Ol}$ gabbros.
Sparse minerals presenting intragrain deformation, such as tapered twins in $\mathrm{Pl}$ and subgrain development in $\mathrm{Ol}$ are also locally observed in the samples.

The Upper unit, $274-400$ mbsf, is composed of Ol gabbros with rather homogeneous modal compositions (Figure 3B), and on average $60 \% \mathrm{Pl}, 30 \% \mathrm{Cpx}$, and $10 \% \mathrm{Ol}$. The highest crystalplastic fabric ranks are at the bottom of the unit near the contact with the Lower unit, with a maximum of $\sim 2$ at $367 \mathrm{mbsf}$; the rest of the unit is almost devoid of crystal-plastic and magmatic fabrics. No igneous contacts were observed in this unit. At the very top of the unit at $\sim 275 \mathrm{mbsf}$, the Ol proportions decrease down to $4 \%$ with the presence of more differentiated Ol bearing gabbros (Figure 3B) and the return of crystal-plastic fabric between 271 and 273 mbsf. The initial description by Dick et al. (2000) characterized these last samples as felsic veins, due to the presence of several areas of conjugated veins filled with felsic material crosscutting the primary gabbroic lithology. Closer to the veins, minerals present interaction textures with amphibole rims around $\mathrm{Cpx}$, mostly dissolved $\mathrm{Ol}$ grains and strongly zoned Pl. Similar lithologies have been reported from Atlantis Bank IODP Hole U1473A; those are referred to as "felsic rocks with diffused boundaries (vein-D)” by Nguyen et al. (2018), and interpreted as felsic melt infiltration into solidifying gabbros. More generally in olivine gabbros, mineral textures such as intergrown $\mathrm{Cpx}, \mathrm{Cpx}$ with symplectite textures, $\mathrm{Pl}$ crystals with discordant polysynthetic twins on irregular grain boundaries and/ or complex optical zoning are common (Figures 4A,B). Again, such textures are interpreted as evidence for RPF (e.g., Lissenberg and MacLeod, 2016), and minerals presenting intragrain deformation, such as tapered twins in $\mathrm{Pl}$ and subgrain development in $\mathrm{Ol}$ are also locally observed, but are less common compared to the observations made in the Lower unit. In closing, the Upper unit is homogeneous, lacking strong magmatic, and crystal-plastic fabrics along with intrusive contacts compared with the Lower unit (Figure 3A).

\section{Whole Rock and In Situ Geochemical Compositions}

The 154 whole rock compositions used herein for the Upper and Lower units are from the Shipboard Scientific Party of Leg 118 (1989), Dick et al. (1999), Dick et al. (1991a), Hart et al. (1999), Hertogen et al. (2002), Holm (2002), and Niu et al. (2002), with four additional unpublished ones analyzed at SARM-CRPG (CNRS, Nancy, France). The rare earth element (REE) compositions of both $\mathrm{Ol}$ gabbros and troctolites are all depleted relative to an average primitive MORB from the Atlantis Bank area (value in Supplementary Table S4) and span similar compositional ranges. The $\mathrm{La}_{\mathrm{N}}$ contents of $\mathrm{Ol}$ gabbros vary between 0.12 and 1.09 and between 0.10 and 0.74 for troctolites, and the $\mathrm{Lu}_{\mathrm{N}}$ contents vary between 0.07 and 0.81 for $\mathrm{Ol}$ gabbros and between 0.1 and 0.86 for troctolites (see Supplementary Table S1). Likewise, samples of both lithologies present weak to strong positive $\mathrm{Eu}$ anomalies, which vary between 0.41 and 2.93 with an average of 1.60 for $\mathrm{Ol}$ gabbros and 1.89 for troctolites. Both units present $\mathrm{Ol}$ gabbro and troctolite samples with weak to strong cumulative signatures in REE, a geochemical cumulate character of the lithologies that was 
A

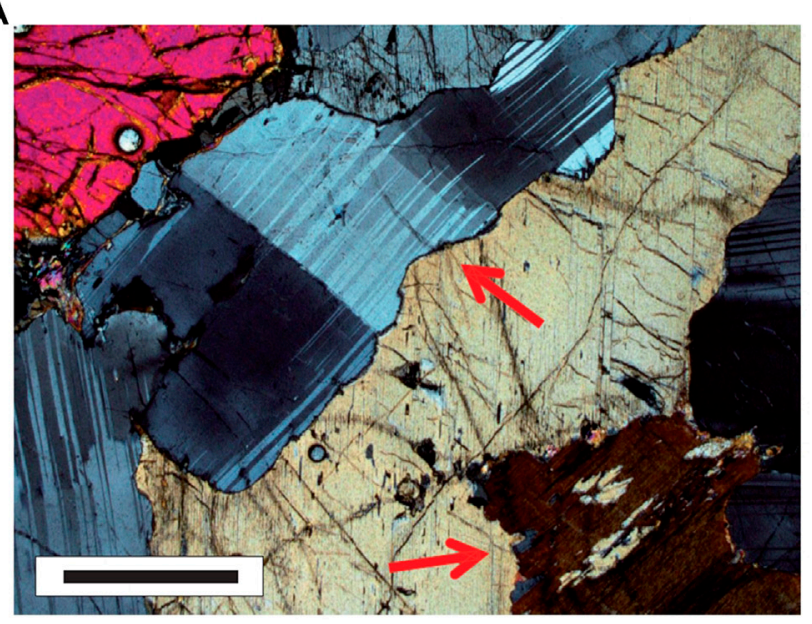

C

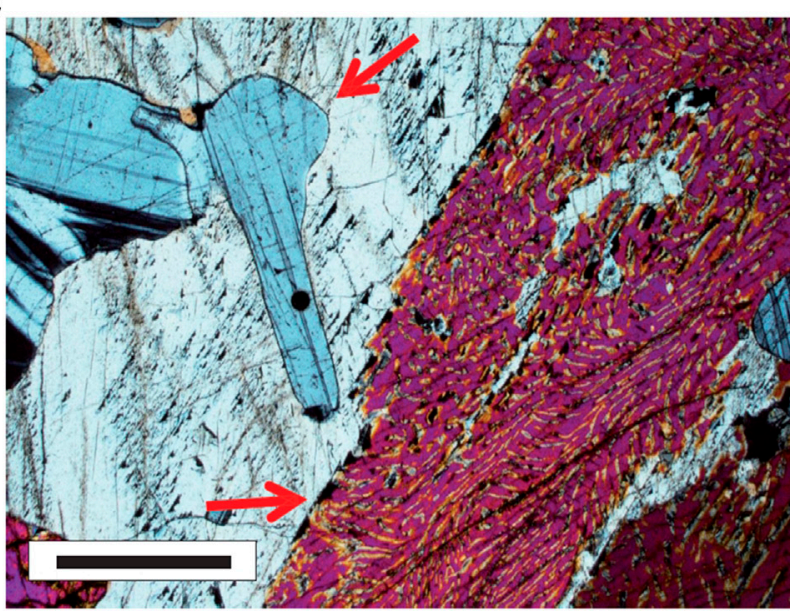

B

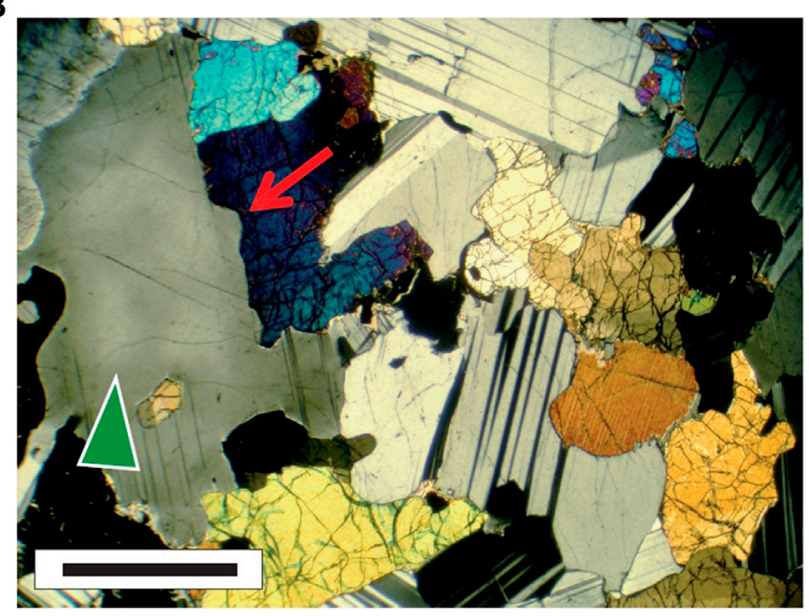

D

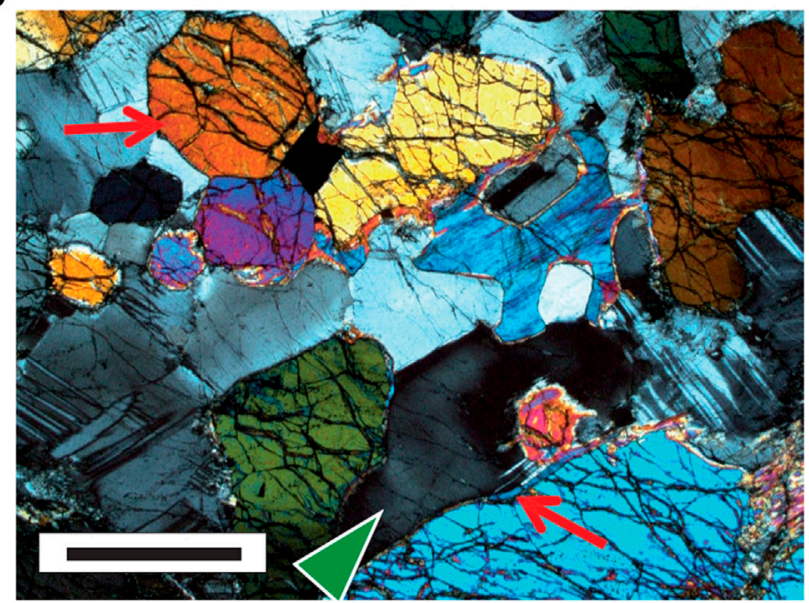

FIGURE 4 | Microphotographs in polarized light of samples from the Upper unit (A,B) and the Lower unit (C,D). Scale bar: 500 um. All samples have magmatic fabrics and crystal-plastic fabrics ranks of 0. (A) Sample 735B-60R-4, $115 \mathrm{~cm}$ (295.38 mbsf): plagioclase grain presenting irregular grain boundaries (top red arrow) and clinopyroxenes intergrowth (bottom arrow). (B) Sample 735B-72R-3, 0 cm (358.5 mbsf): plagioclase grain presenting complex zoning (green arrow) and irregular grain boundaries (red arrow). (C) Sample 735B-81R-5, 7 cm (439.24 mbsf): plagioclase grain with irregular grain boundaries (top arrow) engulfed in a clinopyroxene crystal presenting symplectite textures (bottom arrow). (D) Sample 735B-83R-7, 130 cm (462.55 mbsf): Rounded-shape olivine crystals (top arrow) and plagioclase presenting complex zoning (bottom arrows).

also identified by Dick et al. (2000) and Dick et al. (1991a). Compatible element contents (e.g., $\mathrm{Cr}$ ) and $\mathrm{Mg} \#$ recorded in the Lower unit reach higher values compared to the Upper unit, with Cr contents up to $3,670 \mathrm{ppm}$ and $\mathrm{Mg} \#$ up to 86.8 in the Lower unit, whereas in the Upper unit the values reach up to $900 \mathrm{ppm} \mathrm{Cr}$ and 82.9 in $\mathrm{Mg \#} \mathrm{(Figure} \mathrm{5).} \mathrm{This} \mathrm{highlights} \mathrm{a} \mathrm{more} \mathrm{primitive}$ character recorded in lithologies below $\sim 400$ mbsf. Compositions are also more variable in the Lower unit, with, for example, variation ranges in $\mathrm{Cr}$ contents of $\sim 3,500 \mathrm{ppm}$ in the Lower unit and of only $\sim 750 \mathrm{ppm}$ in the Upper unit, and lower minimum $\mathrm{Cr}$ contents reached in the Lower unit. The Upper unit, in contrast, shows a progressive upward decrease in Mg\# (ranging between 82.8 and 67) and relatively uniform compositions through depth in compatible and incompatible trace elements, except in the very top $\sim 50 \mathrm{~m}$ of the unit where, for example, the $\mathrm{Cr}$ contents decrease from $\sim 380$ to $\sim 25 \mathrm{ppm}$ (Figure 5B).
In situ mineral major and compatible trace element compositions of the samples collected in depth along the section (Figure 3) are consistent with whole rock data. The maximum in situ An content of $\mathrm{Pl}$ (An content = molar ratio $\mathrm{Ca} /[\mathrm{Ca}+\mathrm{Na}+\mathrm{K}] \times 100)$, Fo content of $\mathrm{Ol}(\mathrm{Fo}=$ molar ratio $\mathrm{Mg} /$ $[\mathrm{Mg}+\mathrm{Fe}+\mathrm{Mn}] \times 100)$ and of $\mathrm{Mg \#}$ and $\mathrm{Cr}$ contents of Cpx are higher in the Lower unit compared to the corresponding maximum values in the Upper unit (Figure 6). The same parameters are also more heterogeneous in the Lower unit regardless of the lithology considered (troctolite or $\mathrm{Ol}$ gabbro). In addition, the compositional variability recorded in a single sample or at the same depth is much greater in the Lower unit compared to the Upper one. For example, the Cpx Cr contents range between 1,880 and $8,520 \mathrm{ppm}$ at $462 \mathrm{mbsf}$ (variation of $6,640 \mathrm{ppm}$ ), when on average at a single depth the $\mathrm{Cr}$ content only varies $\sim 1,500 \mathrm{ppm}$ in the Upper unit. In the upper $\sim 20 \mathrm{~m}$ of 


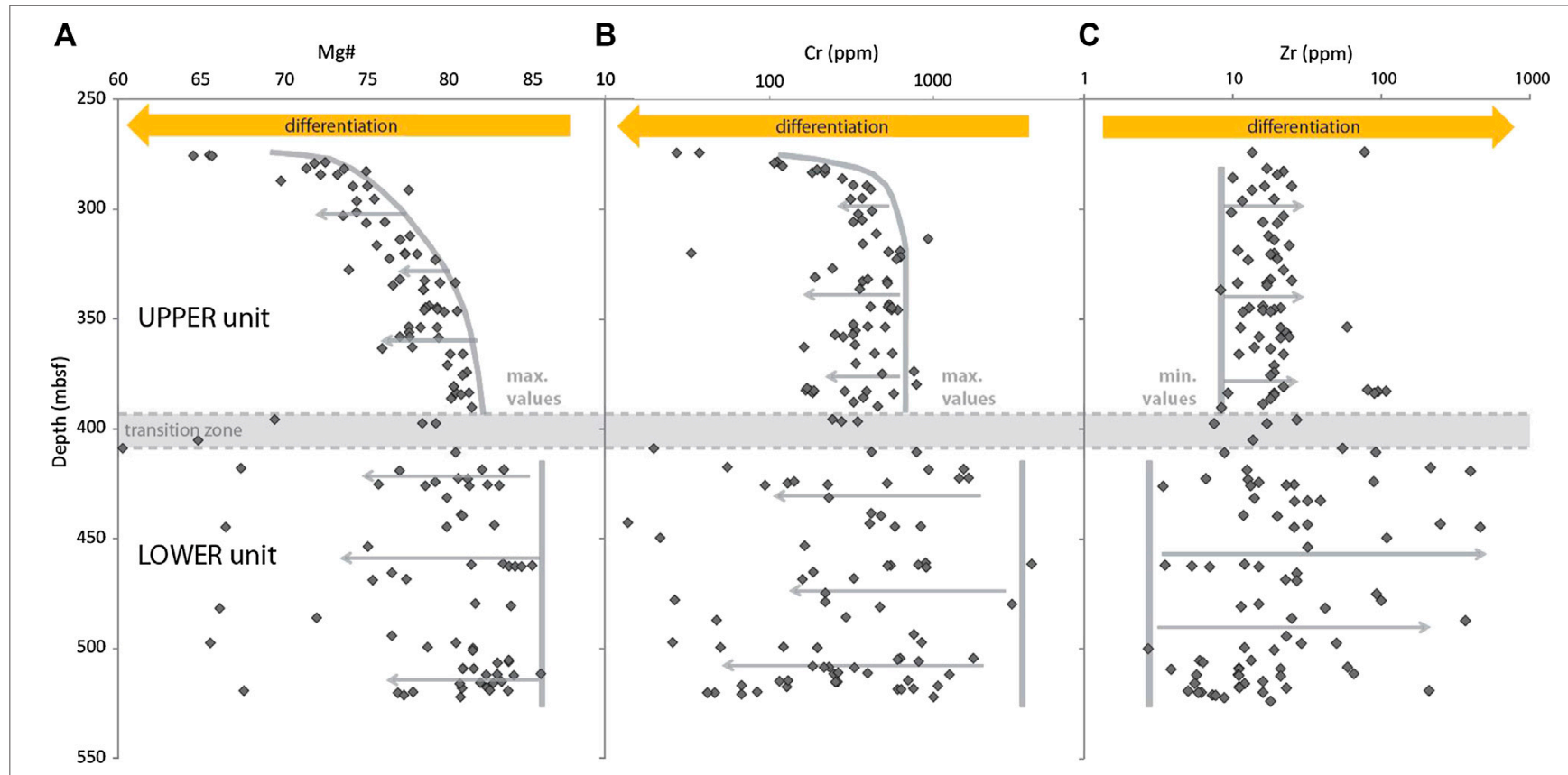

FIGURE 5 |Downhole evolution of whole rock Mg\# (A-molar ratio Mg/[Mg + Fe tot $] \times 100)$, Cr content (B-in ppm) and Zr content (C-in ppm) in Hole $735 B$ Upper and Lower unit. Gray trends represent the more primitive values (maximum or minimum values) and gray arrows the schematic extent of differentiation at a given depth.

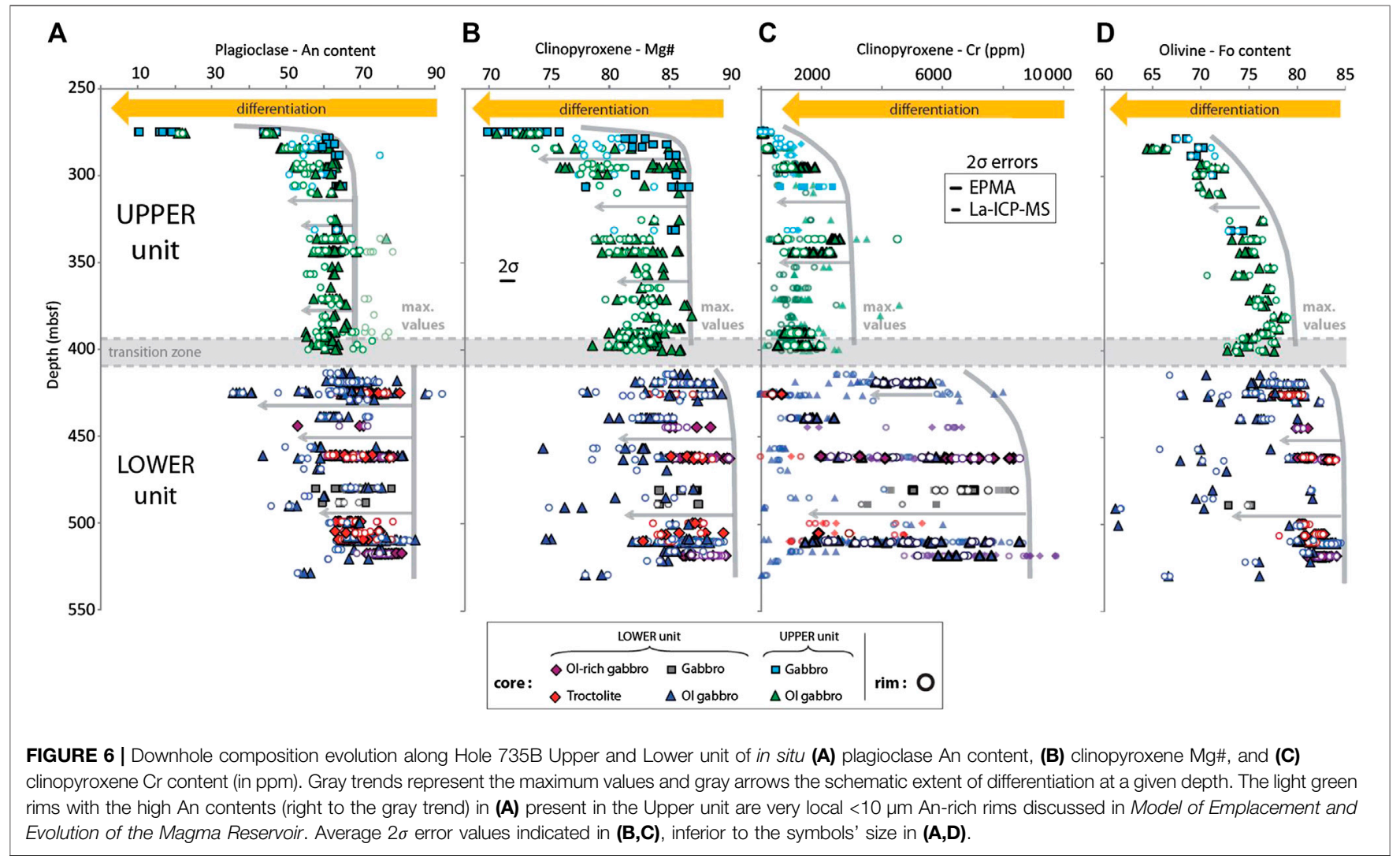




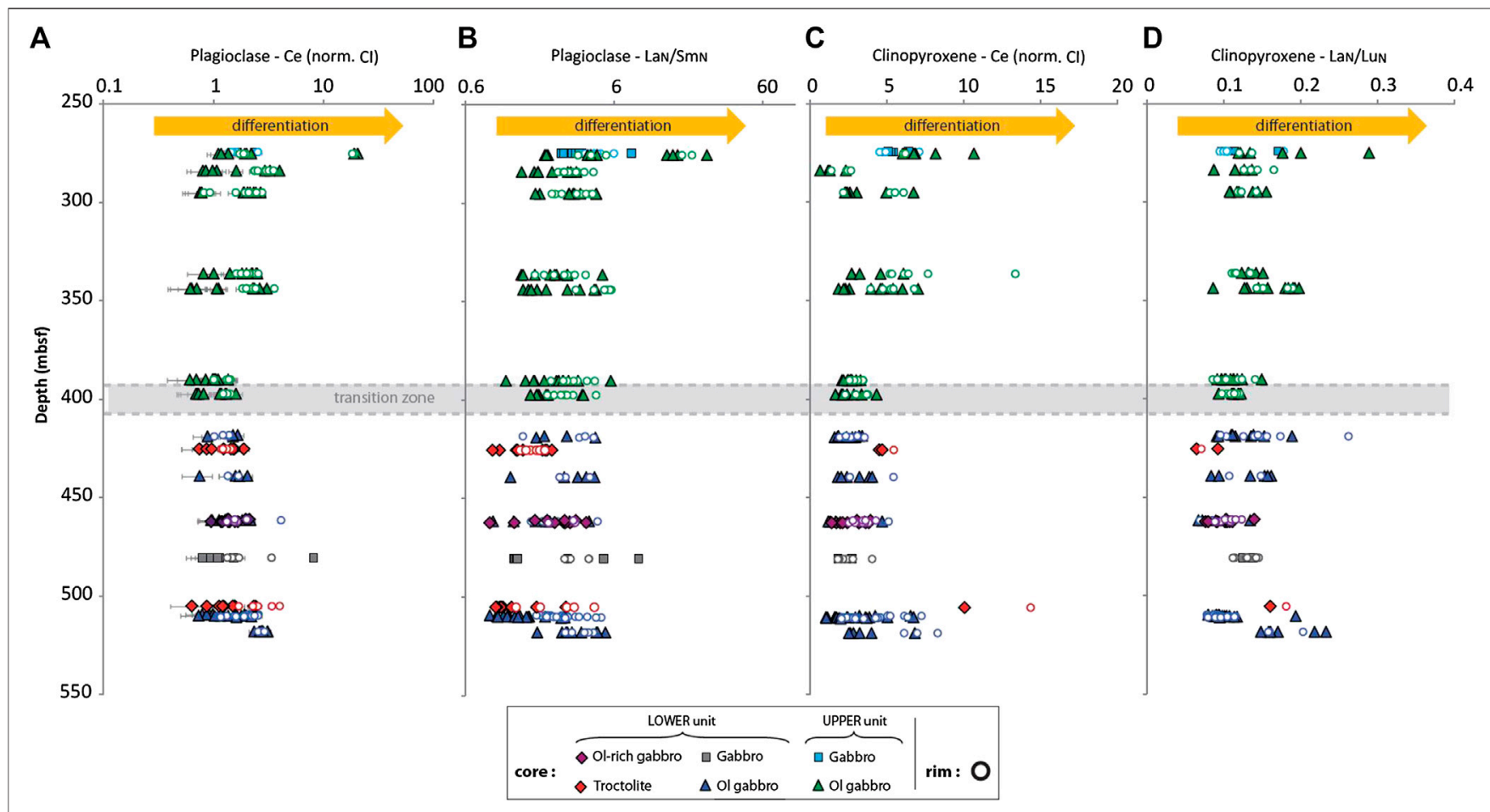

FIGURE 7 | Downhole composition evolution along Hole 735B Upper and Lower unit of in situ (A) plagioclase Ce content, (B) plagioclase ratio La (Light REE) on Sm (Middle REE), (C) clinopyroxene Ce content, and (D) clinopyroxene ratio La (Light REE) on Lu (Heavy REE). Normalization values ( $\mathrm{N}$ ) for Cl chondrites after McDonough and Sun (1995). Average $2 \sigma$ error within the symbols' size on every plot except (A).

the Upper unit, the Cpx Mg\# and $\mathrm{Cr}$ contents and the Pl An content drop to the lowest values recorded in the section (Figure 6). The compositions fall down to $61.9 \mathrm{Mg}$, no $\mathrm{Cr}$, and 10.4 An contents (and 0.2 Or component) in the Ol gabbros crosscut by felsic veins with diffuse boundaries. No clear systematic zoning of the minerals is observed in major and compatible elements in the Lower unit. In the Upper unit below 320 mbsf, no clear systematic zoning is observed, although on average minerals' Cpx rims have slightly lower Mg\# (82.4) than cores (83.3). Above $~ 320$ mbsf, more systematic zoning is observed, with Cpx rims showing lower $\mathrm{Mg \#}$ and $\mathrm{Cr}$ contents (< 82 and $\sim 1,020 \mathrm{ppm}$, respectively) compared to cores (up to 86.6 and $\sim 1,800 \mathrm{ppm}$, respectively-Figure 6). The same tendencies cannot be observed for $\mathrm{Pl}$. Some $\mathrm{Pl}$ grains present, at the very grain boundary, 5-10 $\mu \mathrm{m}$ wide An-rich rims with contents varying between 67 and 79 (Figure 6). These An-rich rims are only observed in the bottom half of the Upper unit.

In situ mineral REE compositions and fractionations are not correlated with depth in the Lower and Upper units. $\mathrm{PlCe} \mathrm{C}_{\mathrm{N}}$ contents vary between 0.6 and 4 all along the section, only one analysis in the Lower unit reaches 8.2, and in the Upper unit the shallowest samples associated with felsic material present $\mathrm{Pl} \mathrm{Ce} \mathrm{N}_{\mathrm{N}}$ contents reaching up to 20.5 ppm (Figure 7A). The same tendency can be described for the $\mathrm{Cpx} \mathrm{Ce}_{\mathrm{N}}$ contents, which vary between 0.7 and $8.2 \mathrm{ppm}$ in both units. Locally the compositions can reach up to $14 \mathrm{ppm}$, such as in the troctolite sample located at $505 \mathrm{mbsf}$ (Figure 7C). The fractionation ranges between light REE and middle REE in $\mathrm{Pl}$ and light REE and heavy REE in Cpx are also very similar between the Upper and the Lower unit. $\mathrm{Pl} \mathrm{La} / \mathrm{Sm}_{\mathrm{N}}$ ratios vary between 0.9 and 6 through the entire section (and reach up to 36.7 for the samples associated with felsic material, Figure 7B), with slightly higher lower bound for the Upper unit (lowest $\mathrm{La}_{N} / \mathrm{Sm}_{N}$ of 1.1). The same tendency can be described for Cpx, with $\mathrm{La}_{\mathrm{N}} / \mathrm{Lu}_{\mathrm{N}}$ ratios varying between 0.07 and 0.23 through the entire section (and reaching up to 0.29 for the samples associated with felsic material, Figure 7D). Incompatible elements are on average more enriched in mineral rims (Figure 7 and 8). This is the case, for example, for Ti in Cpx (average core to rim varies from 4,310 to 5,000 ppm) and $\mathrm{La}$ in $\mathrm{Pl}$ (0.59-0.62 ppm), or Ce in both minerals (2.09-2.49 ppm, and 1.26-1.36 ppm). Cpx Ti contents increase to higher contents for a given $\mathrm{Mg \#}$ in the most primitive minerals of the Lower unit (and especially the rims, with $\mathrm{Mg \#}>85$, up to $1.8 \mathrm{wt} \% \mathrm{TiO}_{2}$ ) compared to the minerals in the Upper unit (Figure 8A). Oppositely, REE content in $\mathrm{Pl}$ varies within similar ranges of compositions for the Upper and Lower units despite significant differences in the minerals' major element contents, as already described above. The $\mathrm{Pl} \mathrm{La} \mathrm{N}_{\mathrm{N}}$ content ranges between 0.58 and 4.35 in the Lower unit for an average mineral's An content of 69.3 (ranging between 10 and 78.9), and ranges between 0.58 and 4.6 in the Upper unit for an average mineral's An content of 55.4 (ranging between 35.6 and 87.7, Figure 8B). 


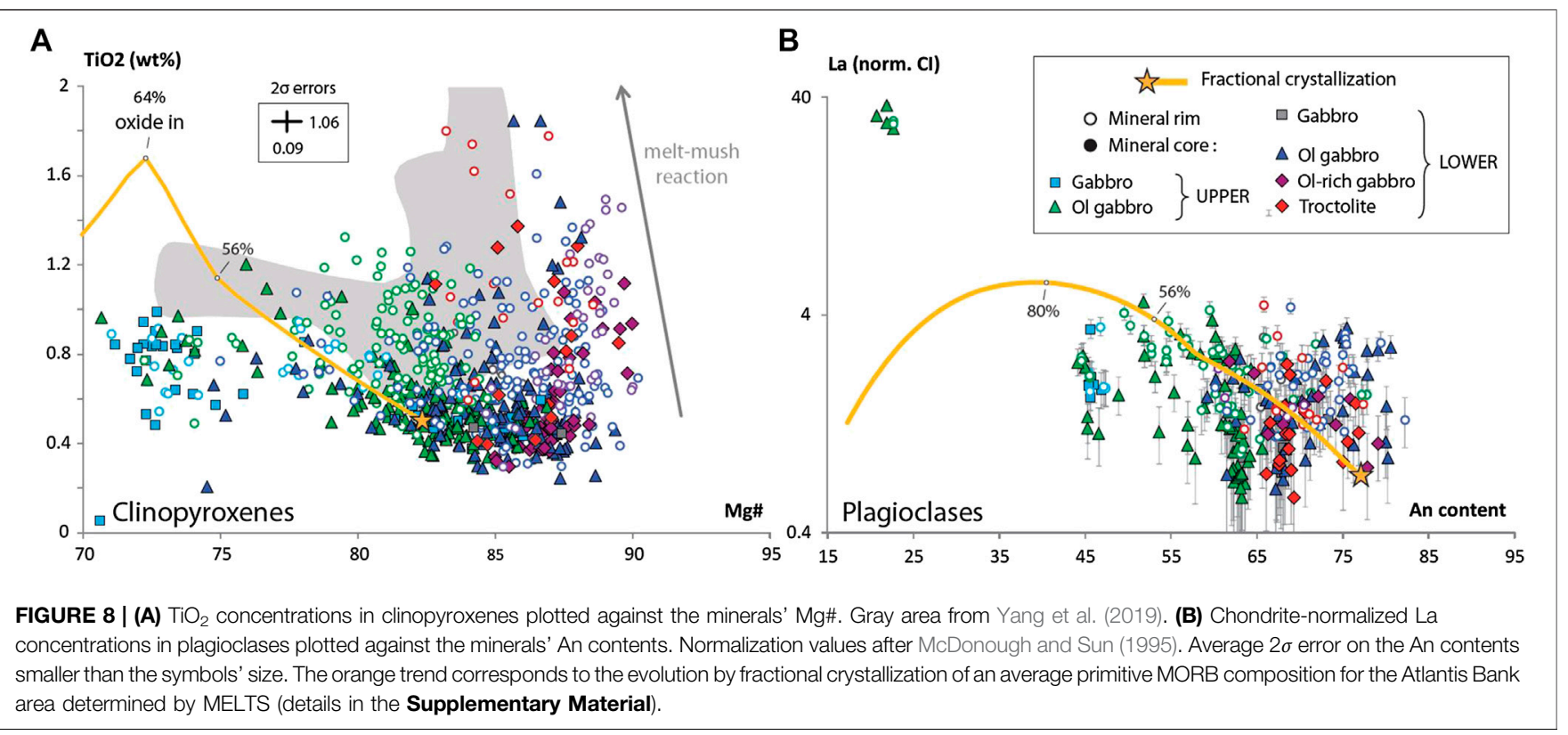

\section{DISCUSSION}

\section{Model of Emplacement and Evolution of the Magma Reservoir}

In the Lower unit ( $125 \mathrm{~m}$ thick) the lithologies range from the most primitive troctolites to $\mathrm{Ol}$ gabbros and gabbros. There is no systematic distribution of the lithologies with depth along the entire unit, which appears highly heterogeneous. A total of 20 intrusive contacts were identified and are almost always associated with the presence of troctolites (Figure 3A). Apart from the sharp transitions between troctolites and more evolved lithologies marked by intrusive contacts, the rest of the sequence is characterized by gradual transitions between the different lithology types within subunits. More specifically, we observed a progressive transition from troctolite to $\mathrm{Ol}$ gabbro between two intrusive contacts at $\sim 510 \mathrm{mbsf}$, where the Cpx content of the samples progressively increases from the bottom toward the upper contact (see Structure and Petrographic Variations and Supplementary Figure S1). Magmatic fabrics of different intensities are also described at various depths within the unit, but no systematic pattern in their distribution or orientation has been identified (e.g., Deans and Yoshinobu, 2019). The whole rock and in situ analyzes also confirm the heterogeneous character of the Lower unit, which presents very large variations in major and both compatible and incompatible trace elements. Again, there is no clear systematic pattern between the compositions recorded in the samples and depth. The most primitive signatures (e.g., higher bound of the compositional ranges in whole rock or $\mathrm{Cpx} \mathrm{Mg \# ,} \mathrm{Pl} \mathrm{An}$ contents, Ol Fo contents, or Cpx Cr contents-Figures 5 and 6) vary in depth, but do not show a progressive evolution up/ down section. The extent of differentiation per sample or at each depth is also variable along the unit.
Altogether, the Lower unit most likely formed from emplacement of sills ( $\sim 6 \mathrm{~m}$ thick in average) at the bottom of the intrusion forming a thick crystal mush and potentially crosscutting one another during emplacement, as indicated by the presence of intrusive contacts and the strong variability in compositions recorded. A sill-like geometry of the intrusions is favored according to seismic observations of such features in the oceanic crust (e.g., Marjanović et al., 2014; Canales et al., 2017; Carbotte et al., 2020), field observations and previous drilled section observations (e.g., Bédard and Hébert, 1996; Boudier et al., 1996; Kelemen et al., 1997; Lissenberg et al., 2004; Sanfilippo and Tribuzio, 2011; Coogan, 2014). In that case, the magmatic fabric would result mainly from crystal orientation due to local flow within each sill (Deans and Yoshinobu, 2019), hence explaining the lack of orientation systematics for the magmatic fabrics in the section. Similar processes producing magmatic fabrics have been described for Atlantis Bank gabbros and quantified by electron backscatter diffraction (EBSD) measurements on a smaller scale by Boulanger et al. (2018). Each sill would have then evolved from bottom to top to various extents, according to the gradual transitions between lithologies and the variable extent of the compositional ranges recorded at depth. Finally, the cumulative geochemical signatures of the lithologies (whole rock REE contents, see Whole Rock and in situ Geochemical Compositions) indicate that melt at some point was extracted from the crystallizing mushes.

In contrast, the Upper unit is homogeneous. The unit is composed of $\mathrm{Ol}$ gabbro except in the top $\sim 20 \mathrm{~m}$ of the sequence which is composed of Ol-bearing gabbro. No igneous contacts or pervasive fabrics are observed; only weak magmatic and crystal-plastic fabrics appear between 350 and $400 \mathrm{mbsf}$ (Figure 3A). Whole rock and in situ analyses confirm the homogeneity of the unit, but show more systematic evolution 
tendencies with depth. Whole rock compositions present progressive upward differentiation trends, as evidenced by the progressive decrease in whole rock $\mathrm{Mg} \#$ (Figure 5A), and are not correlated with depth below 290 mbsf (e.g., $\mathrm{Cr}$ and $\mathrm{Zr}$-Figures 5B,C). Most of the mineral compositions show the same homogeneity with depth (e.g., $\mathrm{Pl} \mathrm{An} \mathrm{contents} \mathrm{and} \mathrm{Mg \#} \mathrm{of} \mathrm{Cpx}$ cores), even though $\mathrm{Ol}$ Fo content, and Cpx rims present a progressively more differentiated character up section. Cpx rims are the last to form in the lithologies, as Cpx is mostly interstitial and hence is the last phase to appear on the liquidus during crystallization; also, given their diffusion rates at magmatic temperature (Dohmen et al., 2007), Ol Mg-Fe contents are likely reequilibrated with the evolving interstitial melt upon differentiation, the same melt that crystallizes the late Cpx. Together with the observed discrepancies between most of the in situ analyses and the progressive upward differentiation

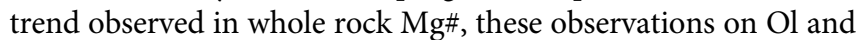
Cpx suggest a progressive accumulation and crystallization of evolved, interstitial melts toward the top of the unit. Only the top $\sim 20 \mathrm{~m}$ of the section record a much stronger differentiated character of the lithologies (very low Pl An contents down to 10, whole rock and $\mathrm{Cpx} \mathrm{Mg \#}$ down to 65 and 70 , respectively-Figures $\mathbf{6 A , B}$ ). The uppermost two samples (275 mbsf) have crosscutting felsic veins which infiltrate the host Ol-bearing gabbro. This interaction with differentiated late-stage melts may account for the local highly evolved compositions of these samples, which have the lowest whole rock $\mathrm{Mg \#}$ of the section (down to 65, Figure 5A).

Altogether, the Upper unit most likely formed during a common magmatic event, and by upward differentiation and accumulation of evolved melts toward the top of the homogeneous mushy reservoir. The homogeneity of the unit suggests crystallization from a single magma batch emplaced within the crust, or multiple incoming melts with similar compositions. The only anomalous features are the very thin, high An content rims that are locally observed at grain boundaries $(\max 10 \mu \mathrm{m})$, and sometimes associated with thin amphibole blebs; those are mostly present in the lower half of the unit (see Whole Rock and in situ Geochemical Compositions). The observation that those An-rich zones are restricted to very narrow grain boundaries suggests a late-stage origin, perhaps by hydrous partial melting, a hypothesis supported by the work on similar features in oceanic gabbros from various settings (e.g., Koepke et al., 2005a; Koepke et al., 2005b; Koepke et al., 2007). Hence, these features likely formed at lower temperatures and thus are considered out of the scope here for our reconstruction of the emplacement and primary magmatic evolution processes of the magma reservoir(s), and will thus not be further discussed herein.

The combined observation of structures, textures and geochemical compositions of the gabbroic sequence reveals critical differences in the melt emplacement dynamics that formed the Lower and the Upper units. The question arising from this observation relates to the link between the two units and the chronology of their emplacement and evolution. Two scenarios are possible: one involves first the formation of the Upper unit by crystallization of a large magma reservoir at depth, then intruded by sills at the bottom of the homogeneous gabbroic sequence. In that case, no direct link between the two units in terms of evolution of the compositions can be drawn. The second scenario involves first stacking of primitive sills, thereby forming the Lower unit, and a subsequent, progressive collection of melts from the sills toward the top of the sequence and formation of the Upper unit. This second option implies a genetic link between melts forming the Lower and Upper units. Previous studies of Hole $735 \mathrm{~B}$, based on whole rock and in situ geochemical compositions of the lithologies, favor the common origin for Upper and Lower unit (e.g., Dick et al., 2000; Natland and Dick, 2002). They interpret the entire section as a "form of cyclic intrusion that differentiated in situ as the magma worked its way upward" (Dick et al., 2000), and an intrusion that was "repetitively injected by comparatively primitive magma" (Natland and Dick, 2002). Other arguments and discussions will be developed in the following sections that tend to favor this last hypothesis (see Origin and Evolution of Melts Within the Upper Unit).

\section{Role of Reactive Porous Flow in the Formation and Evolution of the Reservoir}

Although the two units record different dynamics of magma emplacement, textures and chemistry in both units indicate common, if not ubiquitous occurrence of RPF, regardless of the lithology considered (see Structure and Petrographic Variations, Figure 4). The same type of textures, such as rounded $\mathrm{Ol}$ grains, irregular $\mathrm{Pl}$ grains or intergrown $\mathrm{Cpx}$, have been previously described in Hole 735B and in other gabbroic sections sampled in modern slow-spreading oceanic crust (Lissenberg and MacLeod, 2016 and references therein). They have been interpreted as the result of RPF processes and partial assimilation of crystals during percolation of melt(s) through the permeability of a mush. Together with fractional crystallization (FC), RPF processes are increasingly considered as the predominant processes governing melt differentiation within the lower crust (Lissenberg et al., 2019). Here the implication of RPF is clear from the textures presented above, and in order to test if RPF had also an impact on the chemistry of minerals, we hereafter compare the measured compositions with FC and AFC models. The AFC model of DePaolo (1981) has been commonly used for the study of lower oceanic crust samples as a simplified analogue to the complex RPF processes (Coogan et al., 2000; Kvassnes, 2003; Borghini and Rampone, 2007; Gao et al., 2007; Lissenberg et al., 2013; Sanfilippo et al., 2014; Ferrando et al., 2018). The novelty of our approach resides in our consideration of a sample suite interpreted as representative of an entire magmatic reservoir instead of individual samples, hence helping to better assess the impact of RPF on the differentiation process.

We first modeled the evolution by FC at crustal pressure $(0.2 \mathrm{GPa})$ of a parental melt composition using the rhyoliteMELTS model (Ghiorso and Gualda, 2015; Gualda and Ghiorso, 2015-details in Supplementary Table S4). In order to determine the REE evolution of the melt (and its equilibrium minerals), we used the Rayleigh equation for FC. The phase proportions and partition coefficients were computed at each temperature step of the MELTS model using the composition- 
dependent models of Sun and Liang $(2013,2014)$ for Ol, Sun et al. (2017) for Pl, and Wood and Blundy (1997) for Cpx. The major and trace element compositions of the starting melt were taken to be an average of the most primitive MORBs sampled in the vicinity of Atlantis Bank (from Coogan et al., 2004-details in Supplementary Table S4), and which represent the most likely candidate for the composition of the parental melt forming the section. The results show that $\mathrm{Cpx}$ Ti contents and $\mathrm{Mg} \#$ expected after FC are both lower than the actual content of the minerals from both the Lower and the Upper unit (Figure 8A). These geochemical signatures have already been interpreted as evidence for the occurrence of RPF in lower oceanic crustal sections (e.g., Lissenberg and Dick, 2008; Lissenberg and MacLeod, 2016; Leuthold et al., 2018). High-Mg\# and $\mathrm{Ti} \mathrm{Cpx}$ were also identified by Yang et al. (2019) in the products of interaction experiments between MORB-type melts and a troctolite analog (Figure 8A). They are interpreted as having crystallized from an interstitial high-Ti melt whose major element contents $(\mathrm{Mg} \#)$ were buffered by dissolution of primitive $\mathrm{Ol}$ from the mush analog, hence increasing the melt $\mathrm{Mg}$ content. Regarding the composition of $\mathrm{Pl}$ obtained after FC, the An contents of the minerals are consistent with the data for both the Lower and Upper units (all ranging between An 78 and 45 ). However, the associated $\mathrm{La}_{\mathrm{N}}$ contents of the same $\mathrm{Pl}$ grains show a progressive increase during FC that is not observed in the natural rock record.
For the highest An contents from the Lower unit, the $\mathrm{La}_{\mathrm{N}}$ contents of the $\mathrm{Pl}$ are up to four times higher than the expected value for FC. Conversely, for the Upper unit, almost all the $\mathrm{La}_{\mathrm{N}}$ contents range below the expected value at given $\mathrm{An}$ contents after an evolution by FC (Figure 8B). Hence, the majority of both $\mathrm{Pl}$ and $\mathrm{Cpx}$ signatures fail to be reproduced by FC alone. Together with the characteristic textures observed throughout the section, this result suggests that RPF processes strongly impact the evolution of the Lower and the Upper unit of the reservoir. In the following, we test this hypothesis and attempt to define the reactions involved.

\section{Evolution of Melts Within the Lower Unit}

The widespread involvement of RPF in the evolution of the Lower unit is supported by the pervasive reactive textures found in the samples, and by the major and minor element compositional trends that fail to be reproduced by simple FC models. In order to better constrain the reactions involved, and the extent of RPF in the sequence, we modeled the evolution of the minerals' REE contents after both FC (following the procedure described before) and AFC, and compared them with the natural compositions recorded in our samples. We focused on $\mathrm{Pl}$ compositions as this mineral is the most abundant in all samples $(58 \%$ on average-Figure 3B), and $\mathrm{Pl}$ is less subject to postcrystallization reequilibration than $\mathrm{Ol}$ due to slower diffusion

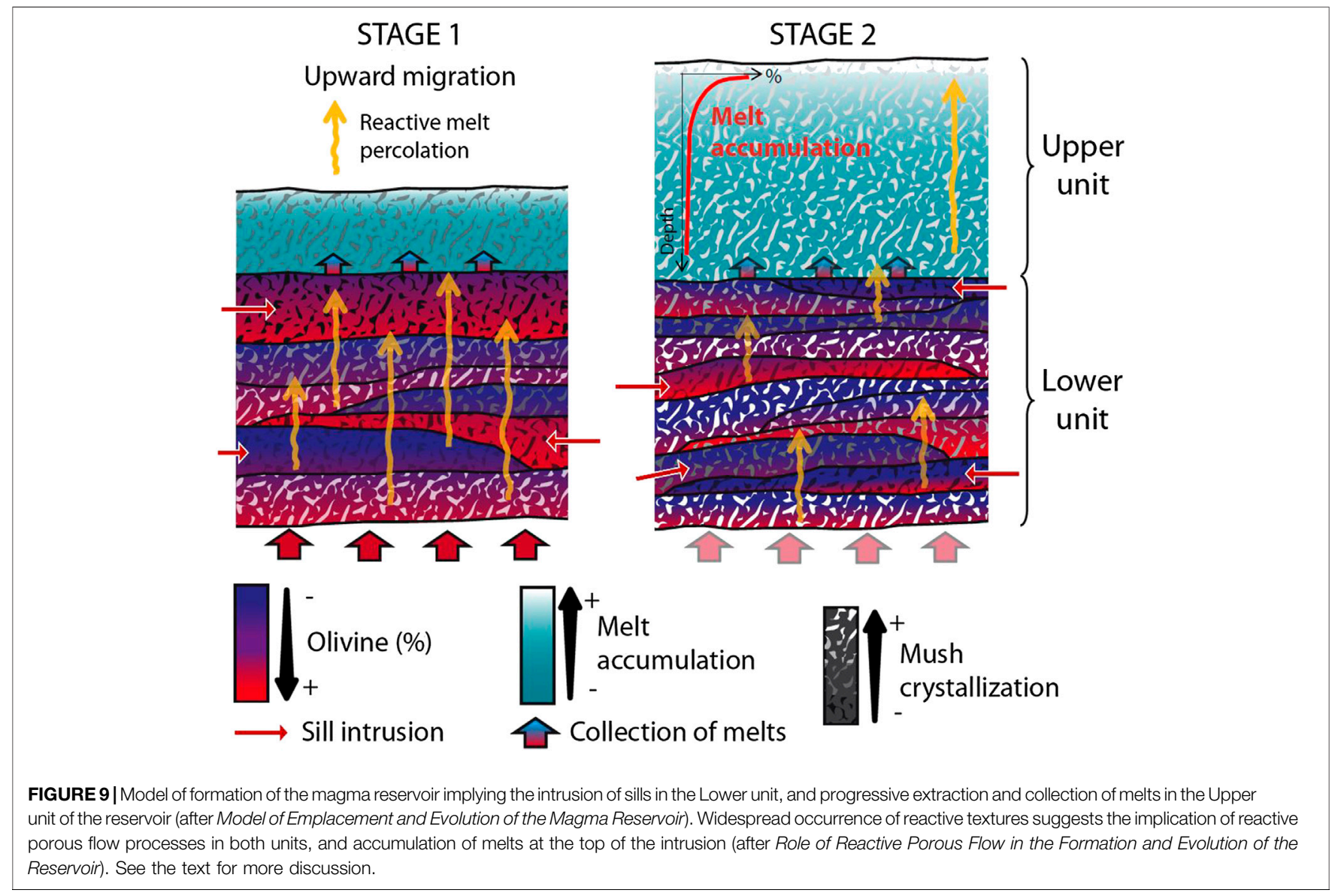



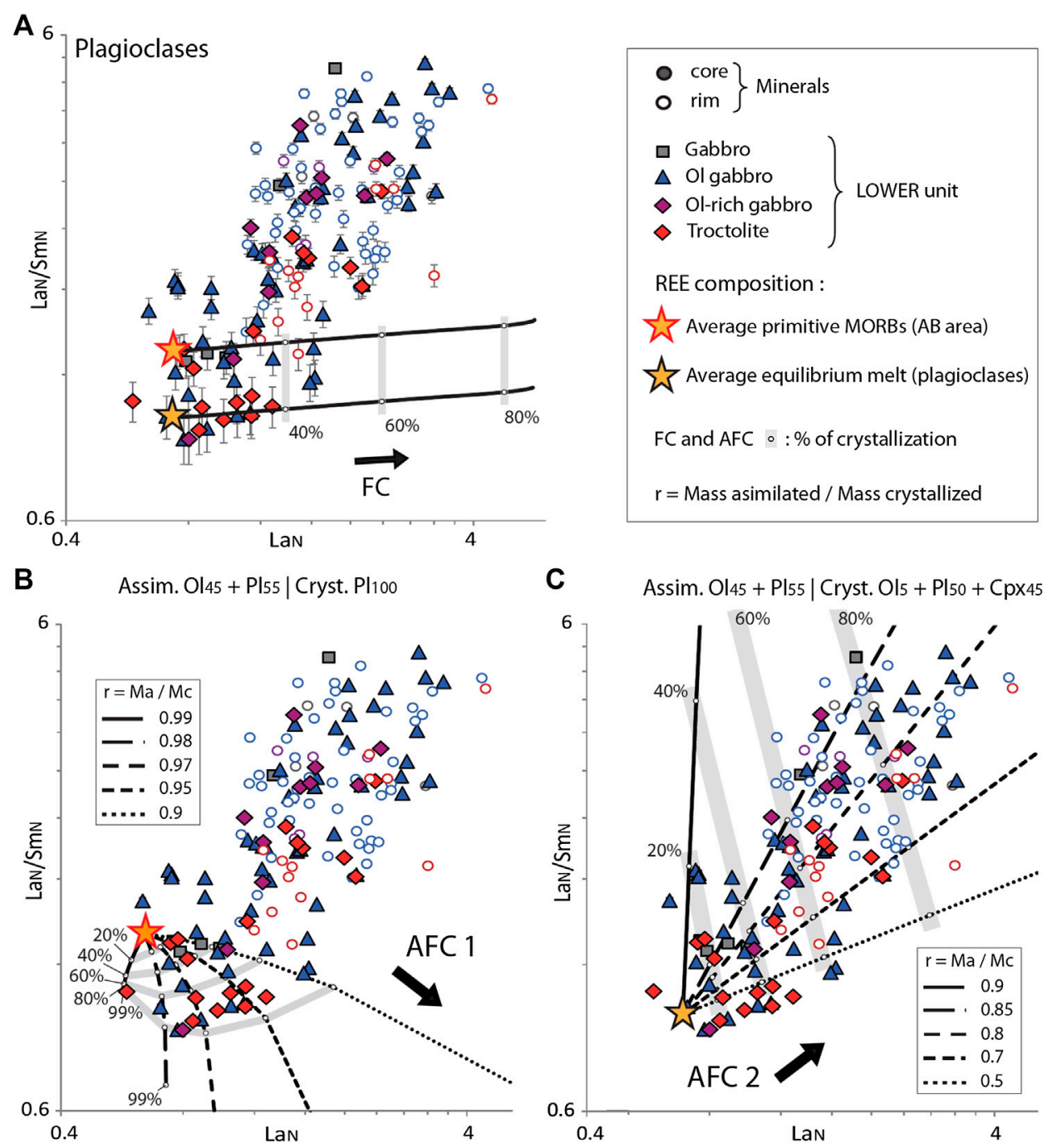

FIGURE 10 $\mathrm{La}_{N} / \mathrm{Sm}_{N}$ ratio vs. LaN analyzed in plagioclases from the Lower unit of ODP Hole 735B [N = normalized to an average primitive MORB composition of the Atlantis Bank area, computed after the MORB data from Coogan et al. (2004)]. (A) Modeling of the plagioclase compositions expected after Fractional Crystallization (FC) from two different parental melts, the average primitive MORB of the Atlantis Bank area (star with red rim), and the melt in equilibrium with the plagioclase presenting the more depleted La compositions and the lower La/Sm ratios (star with black rim). The error bars on the sample analyses represent a $1 \sigma$ error on the values. (B) Modeling of the plagioclase compositions expected after Assimilation-Fractional Crystallization (AFC1) of a troctolitic matrix (45\% olivine $+55 \%$ plagioclase) by the average primitive MORB-type melt (star with red rim) with crystallization of plagioclase exclusively. (C) Modeling of the plagioclase compositions expected after Assimilation-Fractional Crystallization (AFC2) of a troctolitic matrix (45\% olivine $+55 \%$ plagioclase) by the melt in equilibrium with the more depleted plagioclases (star with black rim) with crystallization of a gabbroic assemblage ( $5 \%$ olivine $+50 \%$ plagioclase $+55 \%$ clinopyroxene). Details in Supplementary Material.

of the REE (e.g., Cherniak, 2003; Spandler and O’Neill, 2010). Cpx is classically used for such models, but the very low amount of Cpx in troctolites and its interstitial position in our Ol-rich samples seems to point to a relatively late stabilization in comparison to the large $\mathrm{Pl}$ laths. $\mathrm{Pl}$ are thus more likely to record the early stages of evolution than $\mathrm{Cpx}$ and to cover the entire reservoir evolution history, and they are therefore used herein to track RPF. Light REE and heavy REE are usually used to highlight incompatible element fractionations, however as HREE are strongly depleted in $\mathrm{Pl}$, we will hereafter rather consider light REE and middle REE ( $\mathrm{La} / \mathrm{Sm})$.
The REE evolution by FC was modeled following the same approach as the one presented above (Model of Emplacement and Evolution of the Magma Reservoir and further details in Supplementary Table S4). The global partition coefficient of the crystallized mass was thus calculated for each increment of fractionation with composition-dependent models (Wood and Blundy, 1997; Sun and Liang, 2013; Sun and Liang, 2014; Sun et al., 2017), and was then used to determine the composition of the crystallizing minerals. Two initial REE contents were considered, first the same average composition of primitive MORB-type melts from the Atlantis Bank area as used before 
(see Model of Emplacement and Evolution of the Magma Reservoir), and second the average composition of melts in equilibrium with the $\mathrm{Pl}$ crystals which have the lowest $\mathrm{La}$ contents and $\mathrm{La} / \mathrm{Sm}$ ratios of the unit, i.e., the most primitive signatures. To obtain the composition of these equilibrium melts we used the partition coefficient model of Sun et al. (2017) for each mineral at a chosen temperature of $1,100^{\circ} \mathrm{C}$. The $\mathrm{FC}$ results for both starting melt compositions show that the evolution by FC fails to reproduce the REE compositional ranges of $\mathrm{Pl}$, and more specifically the progressive increase of fractionation between more to less incompatible REE that we quantify with the La/ $\mathrm{Sm}$ ratio (Figure 10A).

To test the RPF hypothesis and to better constrain the reactions involved, we applied the AFC model (DePaolo, 1981) to simulate an evolution by assimilation of a preexisting crystal matrix by a disequilibrium melt, and simultaneous crystallization of a new generation of minerals. The input parameters of the model are the composition of the percolating melt, the type, composition and proportion of assimilated phases, and the mineral species crystallized during the reaction (Supplementary Table S5). The output parameters obtained by fitting the trace elements of natural samples will be the proportions of crystallizing minerals and the $r$ value $(r=$ Mass assimilated/Mass crystallized ratios). We first determined the type of reaction involved, i.e., the nature of the assimilated and crystallized phases, using the textural evidences for RPF found in the Lower unit (Figure 4). Dissolution features can be found for $\mathrm{Ol}$ and $\mathrm{Pl}$ crystals, such as irregular $\mathrm{Pl}$ grain boundaries and complex optical zoning due to the presence of "ghost" $\mathrm{Pl}$ cores remnants, or numerous roundish $\mathrm{Ol}$ chadacrysts in $\mathrm{Pl}$ and/ or Cpx oikocrysts (see Structure and Petrographic Variations and Supplementary Figure S3), suggesting $\mathrm{Pl}$ and $\mathrm{Ol}$ are involved in the assimilation step of the reaction. Conversely, the presence of $\mathrm{Pl}$ overgrowths, the very interstitial character of Cpx in some samples, the lack of Cpx core relicts and the occurrence of $\mathrm{Pl}$ and Cpx oikocrysts containing dissolved $\mathrm{Ol}$ and/or $\mathrm{Pl}$ chadacrysts suggest that both $\mathrm{Pl}$ and Cpx crystallized during the reaction. These observations are also consistent at a larger scale with the changes of the modal compositions and the progressive increase in Cpx abundances toward the top of the sills from the Lower unit (Figure 3B; Supplementary Figure S1). The general reaction considered here based on petrographic constraints is as follow (LU for Lower unit):

$$
\mathrm{Ol}_{1}^{\mathrm{LU}}+\mathrm{Pl}_{1}^{\mathrm{LU}}+\mathrm{melt}_{1}^{\mathrm{LU}} \rightarrow \mathrm{Ol}_{2}^{\mathrm{LU}}+\mathrm{Pl}_{2}^{\mathrm{LU}}+\mathrm{Cpx}^{\mathrm{LU}}+\mathrm{melt}_{2}^{\mathrm{LU}}
$$

The composition of the assimilated phases was chosen to represent a relatively primitive crystal mush composed of $\mathrm{Ol}$ and Pl. We selected the composition of minerals determined by MELTS after $\sim 12 \%$ FC from the average primitive MORB of the Atlantis Bank area, which corresponds to crystallization of $45 \% \mathrm{Ol}$ and $55 \% \mathrm{Pl}$. This ratio is in rather good agreement with the dissolved $\mathrm{Pl} / \mathrm{Ol}$ ratios determined by Yang et al. (2019) and the faster dissolution of $\mathrm{Pl}$ compared to $\mathrm{Ol}$ suggested by Donaldson (1985). The equation itself is also consistent with AFC equations previously established from lower oceanic crust samples (e.g., Lissenberg and Dick, 2008; Leuthold et al., 2018). In addition, we used the REE partition coefficients calculated for the average compositions of $\mathrm{Ol}, \mathrm{Pl}$, and $\mathrm{Cpx}$ analyzed in the Lower unit using the composition-dependent models described above at $1,100^{\circ} \mathrm{C}$. The same two melt REE compositions considered in the FC models were tested here as the reactive melt composition in the AFC model.

We first tested an AFC model considering reaction 1, with percolation of a melt with the composition of the average primitive equilibrium melt through the troctolitic mush (AFC2-Figure 10C). One of the outputs of the AFC model that can be obtained by fitting the mineral trace element contents is the proportion of the crystallizing phases; the best fit $(5 \% \mathrm{Ol}, 50 \% \mathrm{Pl}$, and $45 \% \mathrm{Cpx})$ is consistent with the average modal composition of $\mathrm{Ol}$ gabbros. With this balance, the model manages to reproduce the entire compositional range recorded in the samples for Mass assimilated/Mass crystallized ratios of $0.5-0.99$, and especially matches the increase of fractionation between more to less incompatible REEs (AFC2-Figure 10C). The lack of systematic variation of $\mathrm{La}$ or $\mathrm{La} / \mathrm{Sm}$ with depth through the Lower unit (both high and low values at each depths) also highlight that the RPF process is widespread and of variable extent at depth. The variations in Mass assimilated/Mass crystallized ratios ( $r$ values in Figure 9) potentially highlight a progressive change of the RPF dynamics. A decrease of $r$ value might reflect a progressive closure of the crystal matrix porosity during the reaction, and the promotion of crystallization over assimilation due to a decrease of the percolating melt flow. The variations might also reflect the heterogeneous character of the reaction in space, and the presence of areas with enhanced percolation or areas of preferred crystallization. Intervals of enhanced percolation may directly correlate to areas of textural equilibrium or melt-present deformation. Cheadle et al. (2004) demonstrated that a cumulate pile is permeable down to very low porosities, on the order of $5 \%$, if the cumulate minerals are in textural equilibrium. Textural equilibrium may cease during RPF reactions, leading to the closure of the cumulate pile to incoming melts. Melt-present deformation is also likely to play a role in the permeability of a cumulate pile demonstrated by models by Zimmerman et al. (1999) and Bruhn et al. (2000) that show deformed samples have a higher permeability compared to undeformed samples, and that melt in pockets once interconnected by shearing can flow through pores based on imposed stress fields. We therefore suggest that melt-present deformation increased the permeability of the cumulate pile and also provided a stress field to help move melt through the system.

Even though this specific AFC2 model manages to reproduce the entire compositional range of the Lower unit, we observed that the modal compositions of the lithologies recovered are highly heterogeneous (see Structure and Petrographic Variations and Figure 3B). The type of reactive textures encountered is also correlated to the modal composition of the sample considered. The $\mathrm{Ol}$ crystals which are the most heavily rounded, which we interpret as being dissolved, are found in the Ol-rich lithologies, together with resorbed $\mathrm{Pl}$ grains, poikilitic $\mathrm{Pl}$, and rarer poikilitic Cpx (Figure 4). The texture of these samples indicates that $\mathrm{Pl}$ is the main phase to crystallize during the AFC process in those specific Ol-rich samples. In addition, the percolating melt composition is taken in AFC2 as the average primitive 
equilibrium melt of the unit, and the use of an equilibrium melt instead of a natural melt composition for the reaction can be challenged. Hence, we run an additional model in which the initial primitive melt involved in the reaction had the composition of the average primitive MORB from the Atlantis Bank area. The $\mathrm{Pl}$ in equilibrium with this melt shows similar $\mathrm{La}_{\mathrm{N}}$ contents but higher $\mathrm{La}_{\mathrm{N}} / \mathrm{Sm}_{\mathrm{N}}$ compared to the most primitive $\mathrm{Pl}$ analyzed in the unit. In agreement with the characteristic textures of Ol-rich lithologies described above, a model of extensive $\mathrm{Ol}$ and $\mathrm{Pl}$ assimilation and Pl-only crystallization was tested (AFC1-Supplementary Table S5).

$$
\mathrm{Ol}_{1}^{\mathrm{LU}}+\mathrm{Pl}_{1}^{\mathrm{LU}}+\text { melt }_{1}^{\mathrm{LU}} \rightarrow \mathrm{Pl}_{2}^{\mathrm{LU}}+\text { melt }_{2}^{\mathrm{LU}}
$$

This reaction leads to variable increases in the $\mathrm{La}_{\mathrm{N}}$ content of $\mathrm{Pl}$ coupled to a decrease in the $\mathrm{La}_{\mathrm{N}} / \mathrm{Sm}_{\mathrm{N}}$ ratios that enables the reproduction of the most depleted and fractionated primitive $\mathrm{Pl}$ compositions (AFC1-Figure 10B). The occurrence of reaction $\mathbf{2}$ is supported by the textures of the Ol-rich lithologies and by the modal contents in $\mathrm{Pl}$ of some of these lithologies, which exceeds $80 \%$ at different depths within the Lower unit (Figure 3B). Other lithologies that are the most common in the Lower unit require the involvement of widespread reaction 1 for their formation in order to explain the entire compositional range of the section. AFC1 is here considered to be effective for the most primitive lithologies, and thus to proceed first, when AFC2 that reproduced most of the Lower unit plutonic rocks, is proposed to proceed following AFC1.

The exact composition and origin of the initial reactive melt entering the system is difficult to determine. However, according to the model of emplacement determined for the Lower unit (see Model of Emplacement and Evolution of the Magma Reservoir), the presence of this reactive melt is likely linked to the intrusion of sills at depth and the cyclic input of new primitive MORB-type melts in the system, leading to an evolution of the Lower unit governed by RPF processes and the initial reaction between primitive melts and Ol-Pl crystal matrices. Some late Ti-rich melts are also likely involved in the formation of the high-Mg\# Cpx presenting the highest Ti contents of the unit ( $>1 \mathrm{wt} \%)$, and are probably genetically related to the late formation of the oxide gabbros that are restricted to the Lower unit (see Methods and Model of Emplacement and Evolution of the Magma Reservoir). Interstitial Ti-rich melt generation and collection to form oxide gabbros may also be enhanced by focused deformation. Meltpresent deformation is likely to lead to enhanced crystal-liquid separation through forced melt removal leading to increased differentiation (differentiation by deformation; Bowen, 1920; Dick et al., 2000) forming Fe-Ti enriched fluids. This forced differentiation may explain the higher proportion of oxide gabbros in the Lower unit, which has an abundant record of high temperature deformation, compared to the Upper unit, which has a lack of high temperature deformation.

\section{Origin and Evolution of Melts Within the Upper Unit}

The first order petro-structural observations, and related geochemical constraints at Hole 735B (e.g., Figure 2) have led Dick et al. (2000) and Natland and Dick (2002) to propose that the Lower and Upper units are genetically related. Also, both the more primitive character of the Lower unit and the widespread evidence for melt extraction observed in this unit, together with the more evolved character of the Upper unit (Figures 5 and 6), suggest that melt(s) feeding the Upper unit may originate from the Lower unit (see Model of Emplacement and Evolution of the Magma Reservoir). In order to test this hypothesis, we determined whether, geochemically, the parental melt(s) of the Upper unit could indeed originate from the Lower unit, and if so, at which stage of evolution melt extraction from the Lower unit occurred. Mineral major element compositions of the Upper unit are more differentiated, with a maximum $\mathrm{Pl}$ An content of 63 (excluding the late-stage high-An rims that are locally observed and attributed to hydrous partial melting; see Whole Rock and in situ Geochemical Compositions), whereas the more primitive An contents recorded in the Lower unit reach up to 87.7. After an evolution by FC, Pl An contents of 63 would correspond to $50 \%$ crystallization of the average primitive MORB-type melt determined by MELTS (same model described previously), the most likely parental melt to feed the Lower unit. However, we determined earlier that RPF is the dominant process during the evolution of the Lower unit, which precludes the collection of a melt in the upper reservoir after just extensive FC.

A key observation to quantify the process that links the Upper unit to the Lower unit is the decoupling between the major and compatible element contents of minerals with their REE contents (Figures 6 and 7). The most depleted $\mathrm{Pl} \mathrm{Ce}$ contents in the Upper unit are similar to those in the Lower unit (Figure 7A), when a marked step is observed between the two units for major and compatible element contents of minerals (Figure 6). The only difference in terms of REE compositions between the calculated parental melts of the two units is the slightly stronger fractionation (represented by the $\mathrm{La} / \mathrm{Sm}$ ratio of $\mathrm{Pl}$ and the $\mathrm{La} / \mathrm{Lu}$ ratio of Cpx, Figures $7 \mathbf{B}, \mathrm{D})$ recorded in the Upper unit (see comparison between the Upper and Lower units compositions in Figure 11B). We proposed earlier for the evolution of the Lower unit a first step of reaction involving stronger assimilation of the initial Ol-Pl matrix by a MORB-type primitive melt, followed by the average reaction of assimilation and crystallization of an Ol gabbro assemblage (Evolution of Melts Within the Lower Unit). We can go further in this reasoning, and assume that a chronological decoupling occurs between the assimilation and the crystallization phase of the reaction in the Lower unit. Such decoupling was already considered by Lissenberg and Dick (2008) for the oceanic environment, based on the work of Edwards and Russell (1998) and Reiners et al. (1995). A major consequence of this decoupling is the conservation or even increase of the melt fraction in the system during the first step of reaction by predominant assimilation that would favor remobilization of material, potentially solids but mostly melt.

Based on the general reaction established for the Lower unit, we tested if a first step of preferential assimilation could lead to the formation of a melt with a composition consistent with the one that fed the Upper unit (see Evolution of Melts Within the Lower Unit; Figure 11A). We computed by mass balance the theoretical compositions of hybrid melts by using the composition of the average primitive MORB, from which 
A

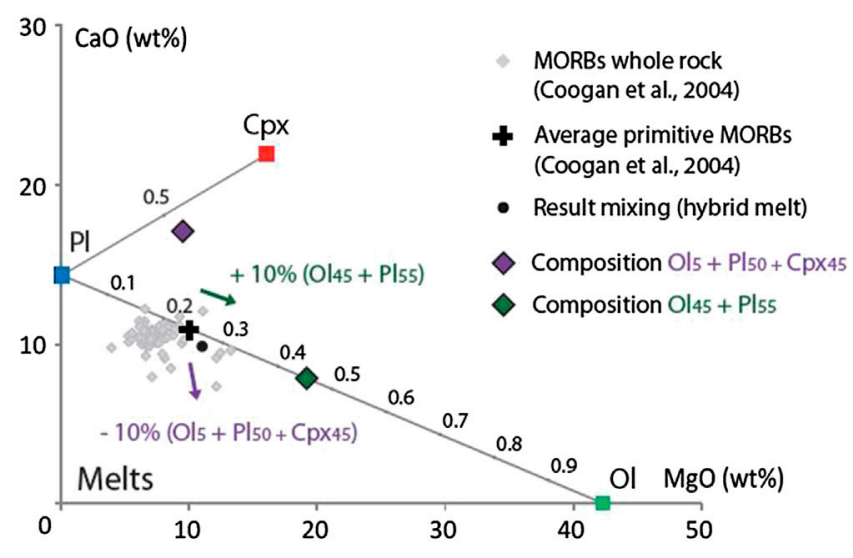

B

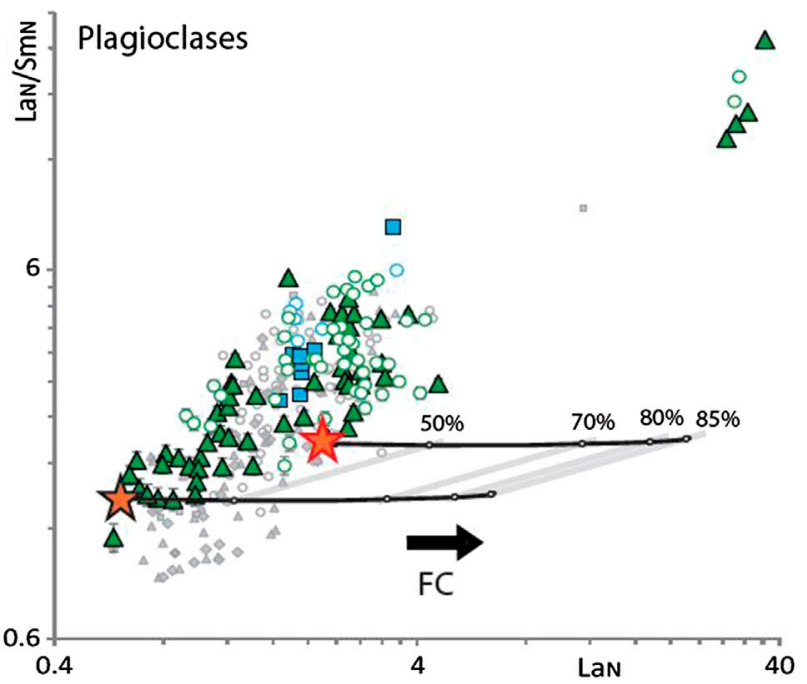

C

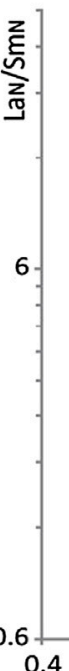

$\left.\begin{array}{ll}0 & \text { core } \\ 0 & \text { rim }\end{array}\right\}$ Minerals

$\left.\begin{array}{l}\Delta \text { Ol gabbro } \\ \square \text { Ol-bearing gabbro }\end{array}\right\}$ UPPER unit

$\square$ LOWER unit compositions

REE composition :

Lower unit AFC 80\% ( $r=0.7)$

解 Average equilibrium melt (plagioclase)

FC and AFC $\circ: \%$ of crystallization

$r=$ Mass asimilated / Mass crystallized

Assim. Ol45 + Pl $55 \mid$ Cryst. Pl55 + Cpx45

FIGURE 11 | (A) Evolution of the composition in $\mathrm{CaO}$ (wt\%) and $\mathrm{MgO}$ (wt\%) of a primitive MORB-type melt after 1) assimilation of a troctolitic component with $55 \%$ plagicolase (PI) and $45 \%$ olivine (OI) (green arrow and diamond), and 2) crystallization of a gabbroic assemblage (5\% Ol $+50 \% \mathrm{Pl}+45 \%$ clinopyroxene-Cpx, purple arrow and diamond). Black line: Mixing line between the Pl and Ol or Pl and Cpx end member compositions. (B,C) LaN/SmN ratio vs. La analyzed in Pl from the Upper unit of ODP Hole 735B [ $N$ = normalized to the average primitive MORB composition of the Atlantis Bank area, computed after the MORB data from Coogan et al. (2004)]. (B) Modeling of the plagioclase compositions expected after Fractional Crystallization (FC) from two different parental melts, the melt in equilibrium with the plagioclase presenting the more depleted La compositions and the lower La/Sm ratios (star with black rim), and a residual melt obtained with the second AFC model (star with red rim-AFC2 in Figure 13). The error bars on the sample analyses represent a $1 \sigma$ error on the values. The gray symbols represent the composition of the plagioclase analyzed in the Lower unit. (C) Modeling of the plagioclase compositions expected after Assimilation-Fractional Crystallization (AFC) of a troctolitic matrix $(45 \% \mathrm{Ol}+55 \% \mathrm{PI}$ ) by the equilibrium melt (AFC3) and the residual melt (AFC4) with crystallization of a gabbro assemblage (55\% Pl and $45 \% \mathrm{Cpx})$. Details in Supplementary Material.

variable proportions of the Ol-Pl assemblage were added (=assimilation of $45 \% \mathrm{Ol}$ and $55 \% \mathrm{Pl}$ ) and from which variable proportions of the gabbroic assemblage were removed (=crystallization of $5 \% \mathrm{Ol}, 50 \% \mathrm{Pl}$, and $45 \% \mathrm{Cpx}$ ). The mineral compositions used for calculations are the average compositions of minerals from the Lower unit (Figure 11A). This equivalent reaction results in hybrid melt compositions that are, for example, slightly enriched in $\mathrm{Mg}$ and depleted in $\mathrm{Ca}$ relative to the initial primitive MORB (Figure 11A). In order to determine if these melts can account for the melt that fed the Upper unit, we modeled their FC by MELTS (Supplementary Table S4) and compared the obtained minerals compositions to the ones of the natural samples. The rationale behind this comparison is to verify if the first phases to crystallize in the Upper unit (i.e., the most primitive $\mathrm{Ol}$ and $\mathrm{Pl}$ ) can crystallize from such hybrid melts.

The best fit to the compositions of the natural samples was obtained by an equivalent $10 \%$ assimilation of the Ol-Pl matrix by the primitive $\mathrm{MORB}$ melt, and $10 \%$ crystallization of the gabbroic assemblage ( $\mathrm{FC}$ of the hybrid melt at $1,150^{\circ} \mathrm{C}, 0.2 \mathrm{GPa}$, and $\left.\left[\mathrm{H}_{2} \mathrm{O}\right]=0.2 \mathrm{wt} \%\right)$. The model shows that the compositions of $\mathrm{Ol}$ and $\mathrm{Pl}$ crystallizing from the hybrid melt are Fo75.5 and An65.8, respectively, when the corresponding compositions in natural samples from the Upper unit are Fo76 and An63 
(Figure 7). The results of the model therefore matches the composition of both $\mathrm{Ol}$ and $\mathrm{Pl}$, but fail to reproduce the composition of natural $\mathrm{Cpx}$ that are enriched in $\mathrm{Mg}$ compared to the first Cpx that crystallize directly from the hybrid melt (Mg\# of 85 and 79.8, respectively). Cpx usually crystallizes later than $\mathrm{Ol}$ and $\mathrm{Pl}$ in the crystallization sequence of primitive MORB-type melts in the lower crust, which is supported here by the more interstitial textures of $\mathrm{Cpx}$ in $\mathrm{Ol}$ gabbros from the Upper unit. The discrepancy between the Cpx compositions likely means that FC is not the predominant process governing the evolution of the Upper unit and that RPF must also be considered, as already suggested by the mineral textures and the geochemical signatures of the Upper unit (see Model of Emplacement and Evolution of the Magma Reservoir). In addition, $\mathrm{Cpx} \mathrm{Mg} \#$ can increase during RPF processes as the $\mathrm{Mg}$ content of a melt increases by assimilation of $\mathrm{Ol}$ as mentioned earlier (Lissenberg and Dick, 2008; Yang et al., 2019). The differentiation processes of the Upper unit will be further quantified in the following.

The associated evolution of the hybrid melt's REE contents expected after an increased assimilation stage (equivalent to $\mathrm{M}$ assimilated/M crystallized $=1$ ) would also explain the decoupling observed between major and trace elements in the section. Higher assimilation of REE-poor materials $(\mathrm{Ol}+\mathrm{Pl})$ associated to smaller fractions of gabbros crystallized, imply relatively stable REE contents of the melt during the reaction despite the simultaneous noticeable changes in the major element contents of the same melt (Yang et al., 2019). This effect could also explain the relatively constant range of La compositions at variable An contents from the Lower to the Upper unit. For example, at low An contents the La concentrations in the $\mathrm{Pl}$ is very low compared to the contents expected after FC (down to $0.58 \mathrm{La}_{\mathrm{N}}$-Figure 8B). However, determining a precise parental melt REE composition for the Upper unit is elusive as the construction of the Lower unit by several sill intrusions, recharge stages, and various amounts of RPF implies a great compositional variability of the melts extracted from the Lower unit. In addition, variable extents of mixing between recharge melts and hybrid melts are likely, especially considering the relatively major element homogeneous character and the lack of igneous contacts in the Upper unit.

We then constrained the evolution of melts collected in the Upper unit following their extraction from the Lower unit. We first modeled evolution by FC (following the method used for FC in Evolution of Melts Within the Lower Unit) of two different starting REE compositions to account for the variability suggested above. The first one is the melt in equilibrium with the average composition of the most primitive $\mathrm{Pl}$ of the Upper unit (lower $\mathrm{La}_{\mathrm{N}}$ contents and lower $\mathrm{La}_{\mathrm{N}} / \mathrm{Sm}_{\mathrm{N}}$ ratios), and the second is a melt composition resulting from the average AFC model applied to the Lower unit (Supplementary Table S5). Both FC models fail to reproduce the compositional range recorded in the Upper unit, and especially the increase of fractionation between more to less incompatible REE that we quantified with the $\mathrm{La}_{\mathrm{N}} / \mathrm{Sm}_{\mathrm{N}}$ ratio (Figure 11B). We then applied two AFC models involving interactions between the latter melts, and an Ol-Pl matrix of the Upper unit $(\sim 1: 1$ identical to reactions 1 and 2$)$ with the following reaction (UU for Upper unit):

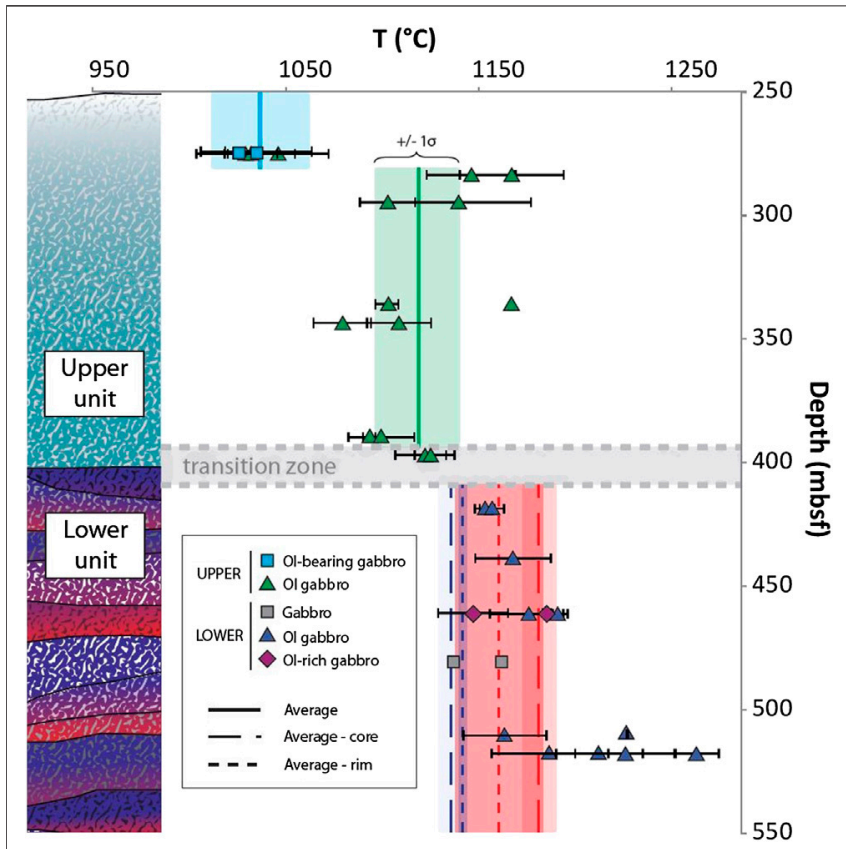

FIGURE 12 | Estimated equilibrium temperatures between PI and Cpx with the thermometer of Sun and Liang (2017) represented with depth. Left: representation of the reservoir structure. Solid and dotted lines represent the average temperatures for lithologies with $>5 \% \mathrm{Cpx}$ in the Upper and Lower unit. $1 \sigma$ errors (error bars and shaded areas) given by the model.

$$
\mathrm{Ol}^{\mathrm{UU}}+\mathrm{Pl}_{1}^{\mathrm{UU}}+\mathrm{melt}_{1}^{\mathrm{UU}} \rightarrow \mathrm{Pl}_{2}^{\mathrm{UU}}+\mathrm{Cpx}^{\mathrm{UU}}+\text { melt }_{2}^{\mathrm{UU}}
$$

We followed the same reasoning for the determination of the models input and output parameters as described for the study of the Lower unit. We considered both $\mathrm{Pl}$ and Cpx crystallization in reaction 3 as the mineral textures described in the Upper unit are similar to those of the Lower unit. Conversely, Ol crystallization was not considered in reaction 3 as the Upper unit is more evolved compared to the Lower unit and the $\mathrm{Ol}$ content tend to slightly decrease toward the top of the section. The best fit of the model results to the REE compositions of the natural samples was obtained for 55 and $45 \%$ crystallization of $\mathrm{Pl}$ and Cpx, respectively. The AFC model involving the equilibrium melt reproduces the entire compositional range of the Upper unit, with ratios of mass assimilated/mass crystallized varying between 0.6 and 0.99 (AFC3-Figure 11C). However, a contribution of melts that previously experienced various steps of evolution by AFC in the Lower unit and that display more enriched and fractionated signatures cannot be excluded. RPF processes involving such melts (e.g., AFC4 in Figure 11C) also reproduce part of the compositional range recorded in the Upper unit with $r$ ratios varying in this case between 0.7 and 0.92. Overall, RPF processes are the predominant processes governing the evolution of the Upper unit, and shape the rock textures, crystal morphologies and compositions, and the modal proportions of rocks. 


\section{Temperature Constraints on the Evolution of the Reservoir}

We estimated the range of temperature experienced by the reservoir during its formation and evolution by applying the REE-in-plagioclase-clinopyroxene thermometer of Sun and Liang (2017). We determined equilibrium temperatures of $\mathrm{Pl}$ and Cpx pairs based on 1) core-core or rim-rim compositions analyzed in the same area of a thin section (32 pairs in total for 15 different samples) and 2) minerals' core and rim average compositions per lithology and per unit (see Supplementary Table S6). The temperatures obtained by the two approaches for the Ol-rich lithologies from the Lower unit, the Ol-bearing gabbros and $\mathrm{Ol}$ gabbro from the Upper unit corresponds to each other (Figure 12). However, the temperatures for the $\mathrm{Ol}$ gabbro samples from the Lower unit range between 1,150 and $\sim 1,260^{\circ} \mathrm{C}$, whereas the temperatures obtained with the average compositions are of only $\sim 1,140^{\circ} \mathrm{C}$. This discrepancy emphasizes that average compositions are not completely irrelevant but need to be checked with spot analyses, especially for lithologies like the Lower unit $\mathrm{Ol}$ gabbros which present a wide compositional variability in major elements. The final results show a temperature range of $\sim 230^{\circ} \mathrm{C}\left(1,260^{\circ} \mathrm{C}\right.$ at the bottom of the Lower unit and $1,026^{\circ} \mathrm{C}$ at the top of the Upper unit) corresponding to the differentiation of the primitive melt down to the temperature range of Ti-rich melts, which later likely segregate and form the oxide gabbros not studied here. The lowest values determined herein correspond to the highest temperatures of formation of the oxide gabbros, as, for example, determined experimentally by Koepke et al. (2018) in a temperature range of $1,050-850^{\circ} \mathrm{C}$. Eventually, the variations of the depth-record of temperature are consistent with the composition-record as more evolved compositions are associated with lower temperature estimates, and ultimately with the reservoir model developed here.

\section{Implications for the Slow-Spreading Lower Oceanic Crust}

\section{Hidden Primitive Cumulates and Differentiation of Primitive MORB}

The more primitive average bulk composition of the lower crust in situ section drilled at the Atlantis Massif OCC (MAR-IODP Hole U1309D) is considered as one of the main differences with the crustal sections drilled at Atlantis Bank. The estimated bulk composition of the plutonic section drilled at Hole U1309D is close to the composition of primary MORB magmas (average bulk crust Mg\# of 72.9-76, Godard et al., 2009). This led Godard et al. (2009) to suggest that no significant fraction of evolved melt escaped the magmatic system sampled at Atlantis Massif. At Atlantis Bank, Dick et al. (2000) and Kvassnes (2003) suggest that the average bulk composition of the cumulate sequence from ODP Hole 735B (and later from IODP Hole U1473A, Dick et al., 2019a) is too evolved with respect to the composition of primary MORB melts (bulk Mg\# of 69.2 for Hole 735B and of 71 for Hole U1473A, Dick et al., 2000). Dick et al. (2000) first infer the presence of a significant mass of "missing" primitive cumulates lying either out of the section or further deep in
Atlantis Bank to account for this difference. The cumulate sequences drilled at Atlantis Bank would then represent already differentiated melts originating from a first step of crystallization at depth, and the theoretical cumulate series that crystallized from the most primitive melts would be absent or at least truncated in the drilled series. This model would also explain the major lack of primitive lithologies drilled at Atlantis Bank such as dunites or troctolites, with troctolites being found only locally in Hole 735B (Dick et al., 2000; MacLeod et al., 2017). Although primitive cumulates are clearly missing when considering the entire ODP Hole 735B drilled at Atlantis Bank, we may wonder if such primitive cumulates are also missing at the scale of the reservoir studied herein. Indeed, we do find primitive cumulates that crystallized in the Lower unit from primitive MORB-type melts. Strikingly, those lithologies were later partially to totally assimilated by reactive percolating melts, and are thus hard to identify. In order to test if the reservoir studied herein is a suitable candidate to represent a lower crust section that record all the key processes related to crustal differentiation, and thus if its bulk composition is similar to primitive MORBs, we quantified this bulk composition.

We approximated the bulk composition of the reservoir, and thus of the Upper and Lower units together, by following the same computation method as Dick et al. (2000). We used the same average bulk composition per lithology and revised interval dimensions by rock type focused on the studied intrusion, after the lithology intervals provided by MacLeod et al. (2017). All lithologies, including oxide gabbros, were considered. The results show that the computed bulk composition of the reservoir is more primitive than the bulk composition of Hole 735B previously determined by Dick et al. (2000), and is comparable to primary MORBs (Table 1). The Mg\# of the reservoir is 72.8, when the value is 72.3 for the primary MORB and of 69.2 for the bulk of Hole 735B. The reservoir bulk composition is also very close to that of Hole U1309D bulk gabbroic composition, which has a Mg\# of 73.2. The Ca\# are more dispersed, with a Ca\# of 73.1 for the reservoir comprised between the Ca\# of the primary MORB and of the bulk Hole U1309D (71.2 and 76.4, respectively). Hence, only regarding the section of Hole 735B representing the reservoir studied herein (Upper and Lower units; Figure 8), no missing primitive cumulate series is required. This result is noteworthy and highlights that one should not always expect large primitive cumulate series (e.g., dunite, troctolite) to be widespread in lower crust sections from slow-spreading centers. Instead, sparse troctolites with abundant olivine gabbros could represent the most primitive cumulates that were partially consumed by RPF. Our new reservoir model also highlights that the scarcity of troctolites is likely related to widespread RPF that occurs since the first stages of the crystallization process, with $\mathrm{Ol}+\mathrm{Pl}$ assemblages being consumed by the reactions. This supports the suggestion made by Dick et al. (2019b) for the entire Hole $735 \mathrm{~B}$ that at least some of the Ol gabbro result from melt interaction processes with more primitive cumulates.

The reservoir model presented herein eventually covers most of the differentiation sequence of primitive MORB-type melts in a slow-spreading environment, apart from the ultimate stages of 
TABLE 1 | Results of bulk rock mass balance calculations for the reservoir of Hole $735 \mathrm{~B}(\mathrm{Mg} \#=100 \times \mathrm{Mg} /(\mathrm{Mg}+\mathrm{Fe}$ tot $)$ with Fe Average primitive MORB after Coogan et al. (2004).

\begin{tabular}{|c|c|c|c|c|c|c|c|c|c|c|c|c|c|c|}
\hline & $\mathrm{SiO}_{2}$ & $\mathrm{TiO}_{2}$ & $\mathrm{Al}_{2} \mathrm{O}_{3}$ & $\mathrm{FeO}$ & $\mathrm{Fe}_{2} \mathrm{O}_{3}$ & $\mathrm{FeO}_{\text {tot }}$ & MnO & MgO & $\mathrm{CaO}$ & $\mathrm{Na}_{2} \mathrm{O}$ & $\mathrm{K}_{2} \mathrm{O}$ & $\mathbf{P}_{2} \mathbf{O}_{5}$ & Mg\# & Ca\# \\
\hline Hole 735B reservoir & 50.12 & 0.76 & 16.50 & 5.47 & 1.25 & 6.47 & 0.13 & 9.71 & 12.75 & 2.60 & 0.04 & 0.02 & 72.8 & 73.1 \\
\hline Calculated primary MORB ${ }^{a}$ & 50.30 & 0.91 & 16.40 & nd & nd & 7.45 & nd & 10.90 & 12.50 & 2.80 & 0.05 & 0.05 & 72.3 & 71.2 \\
\hline Average primitive MORB & 47.86 & 1.33 & 16.30 & - & 10.56 & - & 0.20 & 9.84 & 10.86 & 2.77 & 0.10 & 0.10 & 64.8 & 68.4 \\
\hline Bulk Hole $735 \mathrm{~B}^{\mathrm{a}}$ & 50.60 & 0.87 & 16.10 & 6.19 & 1.37 & 7.31 & 0.14 & 9.21 & 12.50 & 2.80 & 0.05 & 0.05 & 69.2 & 71.2 \\
\hline Bulk Hole U1309D (BG) & 50.18 & 0.67 & 16.69 & - & 7.44 & - & 0.13 & 10.26 & 12.94 & 2.10 & 0.03 & 0.13 & 73 & 77 \\
\hline Bulk Hole U1309D (BG:LD) ${ }^{b}$ & 50.27 & 0.80 & 16.65 & - & 7.34 & - & 0.12 & 9.97 & 12.98 & 2.22 & 0.03 & 0.20 & 73 & 76 \\
\hline
\end{tabular}

aValues after Dick et al. (2000).

${ }^{b}$ Values after Godard et al. (2009).

BG, bulk gabbro composition; BG-LD, bulk gabbro composition with additional contribution of leucocratic dykes; nd, not determined.

evolution documented by the oxide gabbros and felsic veins (e.g., Koepke et al., 2018; Nguyen et al., 2018). One of the questions arising is if this reservoir evolution and associated processes impact the differentiation of the MORBs erupted on the seafloor. The reservoir model itself suggests that if MORBs were extracted from such a reservoir, it is highly unlikely they escaped RPF processes as reactions occur everywhere and at each step of evolution of the reservoir. The issue regarding a possible RPF control on MORB major element signatures (initially only interpreted as originating from different crystallization pressures, e.g., Grove et al., 1992; Villiger et al., 2007) was previously addressed by Lissenberg and Dick (2008). The lowering of Ca contents and increase in $\mathrm{Al}$ and $\mathrm{Mg}$ content suggested during the reactions were also observed experimentally by Yang et al. (2019), and are similar to the major elements evolution modeled herein, for example, to describe the origin of the reactive melts feeding the Upper unit (see Origin and Evolution of Melts Within the

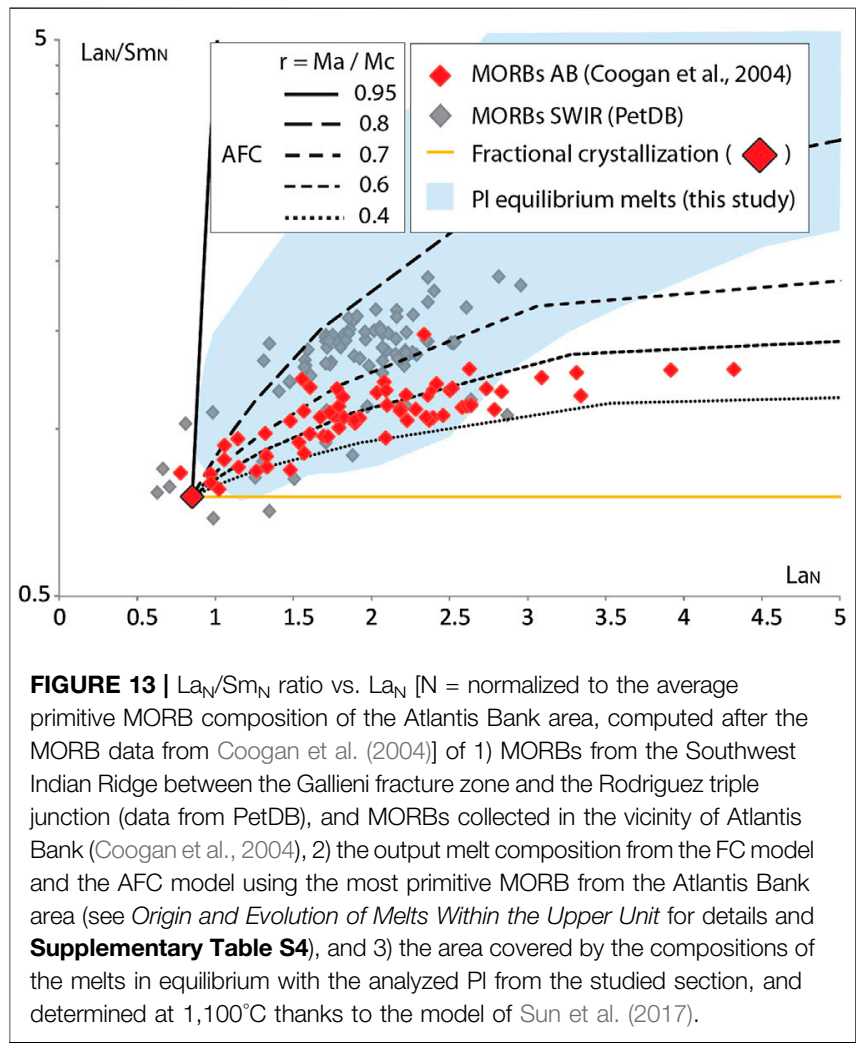

Upper Unit). In order to test if the RPF process identified herein may be recorded in MORB trace elements from the study area, we compared the computed melt compositions obtained by our AFC models and the natural MORB record at Atlantis Bank and the SWIR (Figure 13). We selected the most primitive MORB composition of the Atlantis Bank area (Coogan et al., 2004), and applied the FC and the AFC2 models following the same method used earlier (see Model of Emplacement and Evolution of the Magma Reservoir and Origin and Evolution of Melts Within the Upper Unit). Similarly to what was shown by Lissenberg and Macleod (2016), we show that FC is unable to reproduce the compositional variability of MORBs, whereas the AFC model matches rather well the observed trend. Altogether, our observations are consistent with a widespread implication of $\mathrm{RPF}$ in the lower crustal reservoirs that feed MORBs.

\section{Cyclicity of Magma Inputs and Time Constraints}

The model of reservoir formation proposed herein involves repeated replenishments in the form of small magma intrusions, or sills, during a main magmatic event that led to the formation of the entire unit. Reactive melt percolation appears as the predominant process governing the evolution of melts within the $\sim 200$ m-thick reservoir, and hence melt supply during the main magmatic event was likely sustained, preventing advanced crystallization of each small intrusion and allowing large scale porous migration of melts (Dick et al., 2019a). Even though we bring new constraints on the dynamics of magma emplacement and evolution processes, no time constraint is directly provided by our data. Nevertheless, previous studies that have constrained the timescales of igneous processes at oceanic spreading centers can be used to discuss our reservoir model from a timescale perspective.

At fast-spreading centers, cyclic replenishment of magma chambers has been highlighted based on geochemical data (Rannou et al., 2006). In a review of timescale constraints for magmatic systems of fast-spreading ridges, France et al. (2009) highlighted that different cyclicity periods are likely implicated in the evolution of those systems. Those periods vary from long periods $(\sim 100 \mathrm{ky})$ tentatively related to variations in magma supply from the mantle (e.g., Hooft et al., 1997), to short periods $(\sim 1 \mathrm{ky})$ that may correspond to major magma chamber recharges (e.g., Cordier et al., 2012). Small scale mixing processes, and related recharge events that may be associated with eruption triggering are also identified at the 


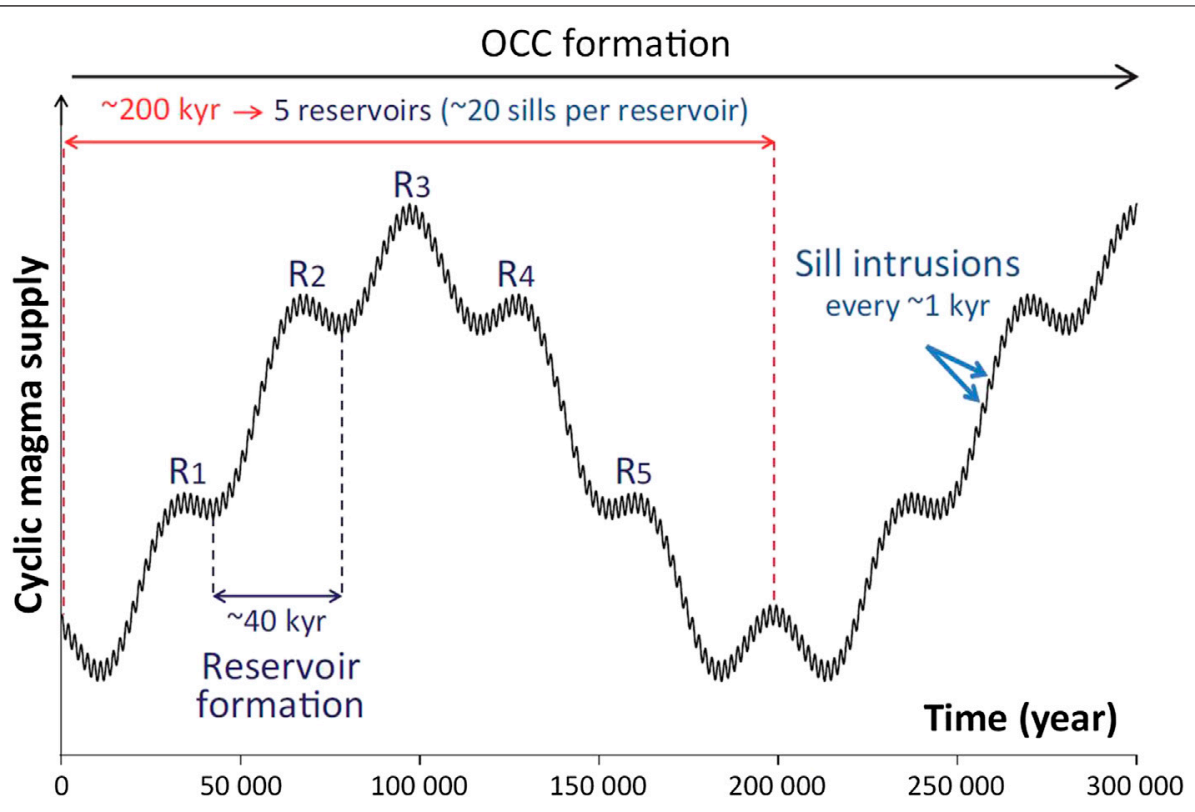

FIGURE 14 | Compilation of the estimated timescales for magma supply below slow-spreading centers, here applied to the Atlantis Bank system and findings on ODP Hole 735B. R, reservoir. See Cyclicity of Magma Inputs and Time Constraints for further details and justification.

scale of 1-10 years (e.g., Costa et al., 2010). The same characteristics of periodicity may apply to slow-spreading environments, but would likely be associated with different timescales. Lower melt supply could indeed imply longer periodicity of melt inputs at the ridge axis.

At slow-spreading centers, Lambart et al. (2019) focused on the isotopic composition of minerals sampled at the Atlantis Massif OCC on the MAR to track the composition of primary melts feeding the crust, which is also discussed by Cordier et al. (2010) who studied the trace element composition of MORBs emplaced at the axis of the slow-spreading Central Indian Ridge. In both cases, whether mantle melts are segregated within the crust or emplaced at the surface, they concluded that melt inputs from the mantle take the form of small magma batches resulting from cyclic melt aggregation in the heterogeneous mantle. In addition, by considering the symmetry of melts' compositions to the ridge axis and the time relations given by magnetic microanomalies at the surface, Cordier et al. (2010) determined a timescale of $150-200 \mathrm{kyr}$ for the aggregation process. This timescale would correspond to the order of magnitude for the periodicity of melt intrusions within the lower slow-spreading oceanic crust, and/or magma replenishment in the lower crust reservoirs. At OCCs, beside the overall cooling rates documented by diffusion chronometry or multi-geochronology tools (e.g., Coogan et al., 2007; Grimes et al., 2011), the only time constraints available for magmatic processes are zircon dates of minerals formed in late-stage lithologies crosscutting the gabbroic sequences. This method enables the estimation of the general age of formation of the structures and the relative emplacement age of the various large-scale intrusions identified. For Atlantis Massif, Grimes et al. (2008) determined that the OCC formation $\sim 1.2 \mathrm{Ma}$ ago lasted for at least
$100-200 \mathrm{kyr}$, and that the age peaks of the two major units forming Hole U1309D are separated by $70 \mathrm{ka}$. In addition, they estimate that based on the number of intrusive contacts in the section and the approximated duration of accretion, the structure potentially formed by on average one sill intrusion ( $\sim 10$ m thick) every 1 kyr. For Atlantis Bank, Rioux et al. (2016) studied zircon ages of Hole $735 \mathrm{~B}$, and Hole 1105A that is the shallowest section (160 m deep) drilled at Atlantis Bank and lies $1.2 \mathrm{~km}$ east-northeast of Hole 735B. The formation of the Atlantis Bank batholith $\sim 12 \mathrm{Ma}$ ago (Schwartz et al., 2009; Rioux et al., 2016) is estimated to have lasted at least $214 \mathrm{kyr}$ (Rioux et al., 2016). This time interval is similar to the estimated duration of crustal accretion for Atlantis Massif described above, but also to the magma emplacement time of $>210 \mathrm{kyr}$ reported for the MARK area (Grimes et al., 2008 and references therein), the 90-235 kyr crystallization timescale recorded at the Vema section of the MAR (Lissenberg et al., 2009), and the 100-200 kyr timescale established by Cordier et al. (2010) for the mantle melt aggregation process. Rioux et al. (2016) also favor the model of episodic growth and formation of the crust at Atlantis Bank by periodic intrusion of "sub-horizontal sheets" of $>250 \mathrm{~m}$ thick, corresponding to the entire reservoir studied herein. Altogether, despite the lack of direct time constraints on the different events of formation of the igneous reservoir described herein, and by analogy with fast-spreading ridges where various periods of process cyclicity is suggested (e.g., France et al., 2009), the previous results on slow-spreading ridges led us to propose a similar scenario.

The formation of the $\sim 1,500 \mathrm{~m}$ thick OCC section drilled at IODP Hole 735B, and possibly the OCC itself is potentially related to cyclic increase of the mantle melt supply, a process with a likely periodicity of $\sim 200 \mathrm{kyr}$ (Figure 14). A shorter 
timescale of a few tens of ky is thus required for the emplacement of each of the large-scale intrusions or reservoirs ( $250 \mathrm{~m}$ thick; 5 units representing part or entire reservoirs at Hole 735B). In this perspective, the repetitive injection of primitive melts feeding the lower crust reservoir, and leading to the formation of the $\sim 20$ sills $(\sim 10 \mathrm{~m}$ thick) in the lower part of the reservoir studied herein (Figure 3 and 9) seems to recur every $\sim 1 \mathrm{kyr}$, which is the same timescale considered for the replenishment of fast-spreading lower crust magma chambers. The relatively continuous replenishment leading to protracted RPF within each of the identified sills likely occurs at a smaller timescale. When considering the reservoir studied herein, the temperature estimates document a cooling of $\sim 230^{\circ} \mathrm{C}$ from the parental magma injection to the temperature range of Ti-rich melts (Figure 12; see Temperature Constraints on the Evolution of the Reservoir). Given the cooling rates documented by Coogan et al. (2007), this corresponds to $\sim 70 \mathrm{ky}$ suggesting that the various reservoirs $(\sim 250 \mathrm{~m})$ intruded each other while melt was still present. Following the same approach we can also estimate the temperature decrease experienced by a given $10 \mathrm{~m}$ thick sill in the time lapse preceding the subsequent sill intrusion $(\sim 1 \mathrm{ky})$. In this case it corresponds to a temperature decrease of $\sim 3^{\circ} \mathrm{C}$ highlighting the potential of interstitial melt percolation from one sill to another upon cooling.

\section{CONCLUSIONS}

We combined high-resolution in situ analyses together with detailed petrographic and structural characterization of a preserved magmatic unit from ODP Hole 735B. The study enabled the establishment of an integrated mush evolution model of a unit formed in the lower oceanic crust of an OCC at a slow-spread ridge. Both melt emplacement processes by intrusion and migration by RPF contributed to its accretion, and strongly influenced the architecture and composition of the reservoir. The principal characteristics of evolution of the igneous reservoir emphasized by the model are as follows:

(1) The lower half of the reservoir represents the initial emplacement of magmas within the slow-spreading crust by repetitive intrusions and sills stacking during a major magmatic event ( $\sim 20$ sills stacked over $\sim 125 \mathrm{~m})$.

(2) The continuous recharge of the lower half of the reservoir has led to assimilation of early primitive liquidus minerals, and to the formation of hybrid melts, which were progressively collected in an overlying mush constituting the upper half of the reservoir.

(3) The upper half of the reservoir has formed by upward differentiation and progressive accumulation of evolved melts, also a product of RPF, toward to the top of the mushy magmatic unit.

Geochemical modeling of in situ incompatible trace element contents enabled the establishment of the strong and ubiquitous involvement of RPF processes in the evolution of the intrusion, and to add further constraints on melt-mush interaction processes that occurred during the evolution of both units. Our results also support models in which MORB melts are affected and record melt-mush interactions and RPF that are identified in the plutonic record. The bulk composition of the studied reservoir is similar to primitive MORBs, and highlight that this specific unit eventually records the entire differentiation series of a slow-spreading center reservoir. Lastly, an attempt to address timescales for the formation of the reservoir is made by comparison with preexisting data and models for magma reservoir at slowspreading ridges. The igneous reservoir model proposed here opens new perspectives for the comprehension of mushdominated igneous reservoirs dynamics in the crust and magma accretion at slow-spreading oceanic centers.

\section{DATA AVAILABILITY STATEMENT}

All datasets presented in this study are included in the article Supplementary Material and/or are available in the OTELo Research Data Repository (FAIR).

\section{AUTHOR CONTRIBUTIONS}

LF has designed the project. MB, LF, and JL have described and collected the samples at the Kochi Core Center (Japan). JD has conducted the structural and textural description of the section at the Kochi Core Center (Japan). MB, AH, and CF have analyzed samples and processed the data. MB has conducted the geochemical modeling, written the manuscript, and prepared the figures. All authors have participated to the manuscript preparation. The models were discussed by all authors, who have approved this submitted manuscript.

\section{FUNDING}

This research was supported by CNRS-INSU and IODP-France. MB's PhD project was funded by the French Ministry of Research (MESRI). JL was supported by the UK Natural Environment Research Council (NERC Grant NE/I001670/1).

\section{ACKNOWLEDGMENTS}

This research used samples and data provided by the Ocean Drilling Program (ODP). ODP was sponsored by the US National Science Foundation (NSF) and participating countries under management of Joint Oceanographic Institutions (JOI), Inc. We acknowledge IODP France funded by CNRS for participating in the funding of this project. The assistance of the staff at the Kochi IODP core repository is gratefully acknowledged. We also express our warm thanks to Jean-Luc Devidal (LMV Clermont-Ferrand) and Olivier Bruguier (Geosciences Montpellier) for their assistance during EPMA and LA-ICP-MS measurements, respectively. This study greatly benefited from thorough reviews by H. J. B. Dick, J. D. 
Blundy, M. R. Perfit, and the editor F. J. Spera, whom we gratefully thank. The authors also thank J. H. Bastin, M. Cannat, K. V. Cashman, H. J. B. Dick, M. Godard, C. J. MacLeod, and A. Sanfilippo for constructive discussions. This is CRPG contribution number 2740 .

\section{REFERENCES}

Baines, A. G., Cheadle, M. J., Dick, H. J. B., Scheirer, A. H., John, B. E., Kusznir, N. J., et al. (2003). Mechanism for generating the anomalous uplift of oceanic core complexes: Atlantis Bank, southwest Indian Ridge. Geology 31, 1105-1108. doi:10.1130/G19829.1

Baines, A. G., Cheadle, M. J., Dick, H. J. B., Scheirer, A. H., John, B. E., Kusznir, N. J., et al. (2007). Evolution of the southwest Indian ridge from $55^{\circ} 45^{\prime} \mathrm{E}$ to $62^{\circ} \mathrm{E}$ : changes in plate-boundary geometry since $26 \mathrm{Ma}$. Geochem. Geophys. Geosy. 8, Q06022. doi:10.1029/2006GC001559

Bédard, J. H., and Hébert, R. (1996). The lower crust of the Bay of Islands ophiolite, Canada: petrology, mineralogy, and the importance of syntexis in magmatic differentiation in ophiolites and at ocean ridges. J. Geophys. Res. 101, 25105-25124. doi:10.1029/96jb01343

Bennett, E. N., Jenner, F. E., Millet, M.-A., Cashman, K. V., and Lissenberg, C. J. (2019). Deep roots for mid-ocean-ridge volcanoes revealed by plagioclase-hosted melt inclusions. Nature 572, 235-239. doi:10.1038/ s41586-019-1448-0

Blackman, D. K., Ildefonse, B., John, B., Ohara, Y., Miller, D. J., and Macleod, C. J. (2006). Site U1309. Proc. Ocean Drill. Progr. 304/305, 304. doi:10.2204/iodp. proc.304305.103.2006

Borghini, G., and Rampone, E. (2007). Postcumulus processes in oceanic-type olivine-rich cumulates: the role of trapped melt crystallization versus melt/rock interaction. Contrib. Mineral. Petrol. 154, 619-633. doi:10.1007/s00410-0070217-5

Boudier, F., Nicolas, A., and Ildefonse, B. (1996). Magma chambers in the Oman ophiolite: fed from the top and the bottom. Earth Planet. Sci. Lett. 144, 239-250. doi:10.1016/0012-821x(96)00167-7

Boulanger, M., France, L., Ildefonse, B., Ghosh, B., Sanfilippo, A., Liu, C. Z., et al. (2018). "Origin of the interlayered series at Atlantis Bank (SWIR): new insights on lower oceanic crust accretion processes," in Goldschmidt2018, Boston, USA, August 2018. Abstract 122.

Bowen, N. L. (1920). Differentiation by deformation. Proc. Natl. Acad. Sci. U.S.A. 6, 159. doi:10.1073/pnas.6.4.159

Bruhn, D., Groebner, N., and Kohlstedt, D. L. (2000). An interconnected network of core-forming melts produced by shear deformation. Nature 403, 883-886. doi: $10.1038 / 35002558$

Canales, J. P., Dunn, R. A., Arai, R., and Sohn, R. A. (2017). Seismic imaging of magma sills beneath an ultramafic-hosted hydrothermal system. Geology 45, 451-454. doi:10.1130/G38795.1

Carbotte, S. M., Arnulf, A., Spiegelman, M., Lee, M., Harding, A., Kent, G., et al. (2020). Stacked sills forming a deep melt-mush feeder conduit beneath Axial Seamount. Geology 48, 693-697. doi:10.1130/g47223.1

Carbotte, S. M., Smith, D. K., Cannat, M., and Klein, E. M. (2015). Tectonic and magmatic segmentation of the Global Ocean Ridge System: a synthesis of observations. Geol. Soc. Spec. Publ. 420, 249-295. doi:10. $1144 / \mathrm{sp} 420.5$

Cheadle, M. J., Elliott, M. T., and McKenzie, D. (2004). Percolation threshold and permeability of crystallizing igneous rocks: the importance of textural equilibrium. Geology 32, 757-760. doi:10.1130/g20495.1

Cherniak, D. J. (2003). REE diffusion in feldspar. Chem. Geol. 193, 1-17. doi:10. 1016/s0009-2541(02)00246-2

Coogan, L. A. (2014). The lower oceanic crust. 2nd Edn. Amsterdam, Netherlands: Elsevier.

Coogan, L. A., Jenkin, G. R. T., and Wilson, R. N. (2007). Contrasting cooling rates in the lower oceanic crust at fast- and slow-spreading ridges revealed by geospeedometry. J. Petrol. 48, 2211-2231. doi:10.1093/petrology/egm057

Coogan, L. A., Saunders, A. D., Kempton, P. D., and Norry, M. J. (2000). Evidence from oceanic gabbros for porous melt migration within a crystal mush beneath

\section{SUPPLEMENTARY MATERIAL}

The Supplementary Material for this article can be found online at: https://www.frontiersin.org/articles/10.3389/feart.2020.554598/ full\#supplementary-material

the Mid-Atlantic Ridge. Geochem. Geophys. Geosyst. 1, 2000GC000072. doi:10. 1029/2000GC000072

Coogan, L. A., Thompson, G. M., MacLeod, C. J., Dick, H. J. B., Edwards, S. J., Hosford Scheirer, A., et al. (2004). A combined basalt and peridotite perspective on 14 million years of melt generation at the Atlantis Bank segment of the Southwest Indian Ridge: evidence for temporal changes in mantle dynamics? Chem. Geol. 207, 13-30. doi:10.1016/j.chemgeo.2004.01.016

Cordier, C., Benoit, M., Hémond, C., Dyment, J., Le Gall, B., Briais, A., et al. (2010). Time scales of melt extraction revealed by distribution of lava composition across a ridge axis. Geochem. Geophys. Geosyst. 11, Q0AC06. doi:10.1029/ 2010GC003074

Cordier, C., Caroff, M., and Rannou, E. (2012). Timescale of open-reservoir evolution beneath the south Cleft segment, Juan de Fuca ridge. Mineral. Petrol. 104, 1-14. doi:10.1007/s00710-011-0159-5

Costa, F., Coogan, L. A., and Chakraborty, S. (2010). The timescales of magma mixing and mingling involving primitive melts and melt-mush interaction at mid-ocean ridges. Contrib. Mineral. Petrol. 159, 173-194. doi:10.1007/s00410009-0432-3

Deans, J. R. L., and Yoshinobu, A. S. (2019). Geographically re-oriented magmatic and metamorphic foliations from ODP Hole 735B Atlantis Bank, Southwest Indian Ridge: magmatic intrusion and crystal-plastic overprint in the footwall of an oceanic core complex. J. Struct. Geol. 126, 1-10. doi:10.1016/j.jsg.2019. 05.001

DePaolo, D. J. (1981). Trace element and isotopic effects of combined warlock assimilation and fractional crystallization. Earth Planet. Sci. Lett. 53, 189-202. doi:10.1016/0012-821X(81)90153-9

Dick, H. J. B., Kvassnes, A. J. S., Robinson, P. T., MacLeod, C. J., and Kinoshita, H. (2019a). The Atlantis Bank Gabbro Massif, Southwest Indian Ridge. Prog. Earth Planet. Sci. 6, 64. doi:10.1186/s40645-019-0307-9

Dick, H. J. B., Macleod, C. J., Blum, P., Abe, N., Blackman, D. K., Bowles, J. A., et al. (2019b). Dynamic accretion beneath a slow-spreading ridge segment: IODP Hole U1473A and the Atlantis Bank core complex. J. Geophys. Res. Solid Earth 124, 12631-12659. doi:10.1029/2018JB016858

Dick, H. J. B., Lin, J., and Schouten, H. (2003). An ultraslow-spreading class of ocean ridge. Nature 426, 405-412. doi:10.1038/nature02128

Dick, H. J. B., Meyer, P. S., Bloomer, S., Kirby, S., Stakes, D., and Mawer, C. (1991a). Lithostratigraphic evolution of an in-situ section of oceanic layer 3. Proc. Ocean Drill. Prog. Sci. Results 118, 439-538. doi:10.2973/odp.proc.sr.118.128.1991

Dick, H. J. B., Schouten, H., Meyer, P. S., Gallo, D. G., Bergh, H., Tyce, R., et al. (1991b). Tectonic evolution of the Atlantis II fracture zone. Proc. Ocean Drill. Progr. Sci. Results 118, 359-398. doi:10.2973/odp.proc.sr.118.156.1991

Dick, H. J. B., Natland, J. H., Alt, J. C., Bach, W., Bideau, D., Gee, J. S., et al. (2000). A long in situ section of the lower ocean crust: results of ODP Leg 176 drilling at the Southwest Indian Ridge. Earth Planet. Sci. Lett. 179, 31-51. doi:10.1016/ S0012-821X(00)00102-3

Dick, H. J. B., Natland, J. H., Miller, D. J., and Al, E. (1999). Site 735. Proc. Ocean Drill. Progr. 176, 1-314. doi:10.2973/odp.proc.ir.176.103.1999

Dick, H. J. B., Ozawa, K., Meyer, P. S., Niu, Y., Robinson, P. T., Constantin, M., et al. (2002). 10. Primary silicate mineral chemistry of a $1.5-\mathrm{km}$ section of very slow spreading lower ocean crust: ODP Hole 753B, Southwest Indian Ridge. Proc. Ocean Drill. Progr. Sci. Results 176, 1-61. 10.2973/odp.proc.sr.176.001.2002

Dohmen, R., Becker, H.-W., and Chakraborty, S. (2007). Fe-Mg diffusion in olivine I: experimental determination between 700 and $1,200^{\circ} \mathrm{C}$ as a function of composition, crystal orientation and oxygen fugacity. Phys. Chem. Miner. 34, 389-407. doi:10.1007/s00269-007-0157-7

Donaldson, C. H. (1985). The rates of dissolution of olivine, plagioclase, and quartz in a basalt melt. Mineral. Mag. 49, 683-693. doi:10.1180/minmag.1985. 049.354 .07

Drouin, M., Godard, M., Ildefonse, B., Bruguier, O., and Garrido, C. J. (2009). Geochemical and petrographic evidence for magmatic impregnation in the 
oceanic lithosphere at Atlantis Massif, Mid-Atlantic Ridge (IODP Hole U1309D, 30N). Chem. Geol. 264, 71-88. doi:10.1016/j.chemgeo.2009.02.013

Dunn, R. A. (2015). "Crust and lithospheric structure - seismic structure of midocean ridges," in Treatise on geophysics. New York, NY: Elsevier, 419-451.

Dunn, R. A., Lekić, V., Detrick, R. S., and Toomey, D. R. (2005). Three-dimensional seismic structure of the Mid-Atlantic Ridge $\left(35^{\circ} \mathrm{N}\right)$ : evidence for focused melt supply and lower crustal dike injection. J. Geophys. Res. Solid Earth 110, 1-17. doi:10.1029/2004JB003473

Edwards, B. R., and Russell, J. K. (1998). Time scales of magmatic processes: new insights from dynamic models for magmatic assimilation. Geology 26, 1103. doi:10.1130/0091-7613(1998)026<1103:TSOMPN>2.3.CO;2

Escartín, J., Mével, C., MacLeod, C. J., and McCaig, A. M. (2003). Constraints on deformation conditions and the origin of oceanic detachments: the MidAtlantic Ridge core complex at $15^{\circ} 45^{\prime} \mathrm{N}$. Geochem. Geophys. Geosyst. 4, 1067. doi:10.1029/2002GC000472

Ferrando, C., Godard, M., Ildefonse, B., and Rampone, E. (2018). Melt transport and mantle assimilation at Atlantis Massif (IODP Site U1309): constraints from geochemical modeling. Lithos 323, 24-43. doi:10.1016/j.lithos.2018.01.012

France, L., Ildefonse, B., and Koepke, J. (2009). Interactions between magma and hydrothermal system in Oman ophiolite and in IODP Hole 1256D: fossilization of a dynamic melt lens at fast spreading ridges. Geochem. Geophys. Geosyst. 10, 1-30. doi:10.1029/2009GC002652

Gao, Y., Hoefs, J., Hellebrand, E., von der Handt, A., and Snow, J.E. (2007). Trace element zoning in pyroxenes from ODP Hole 735B gabbros: diffusive exchange or synkinematic crystal fractionation? Contrib. Mineral. Petrol. 153, 429-442. doi:10.1007/s00410-006-0158-4

Ghiorso, M. S., and Gualda, G. A. R. (2015). $\mathrm{An}_{2} \mathrm{O}-\mathrm{CO}_{2}$ mixed fluid saturation model compatible with rhyolite-MELTS. Contrib. Mineral. Petrol. 169, 53. doi:10.1007/s00410-015-1141-8

Godard, M., Awaji, S., Hansen, H., Hellebrand, E., Brunelli, D., Johnson, K., et al. (2009). Geochemistry of a long in-situ section of intrusive slow-spread oceanic lithosphere: results from IODP Site U1309 (Atlantis Massif, $30^{\circ} \mathrm{N}$ Mid-AtlanticRidge). Earth Planet. Sci. Lett. 279, 110-122. doi:10.1016/j.epsl.2008.12.034

Grimes, C. B., Cheadle, M. J., John, B. E., Reiners, P. W., and Wooden, J. L. (2011). Cooling rates and the depth of detachment faulting at oceanic core complexes: evidence from zircon $\mathrm{Pb} / \mathrm{U}$ and (U-Th)/He ages. Geochem. Geophys. Geosyst. 12 (3), Q0AG01. doi:10.1029/ 2010GC003391

Grimes, C. B., John, B. E., Cheadle, M. J., and Wooden, J. L. (2008). Protracted construction of gabbroic crust at a slow spreading ridge: constraints from $206 \mathrm{~Pb} / 238 \mathrm{U}$ zircon ages from Atlantis Massif and IODP Hole U1309D $\left(30^{\circ} \mathrm{N}\right.$, MAR). Geochem. Geophys. Geosyst. 9, Q08012. doi:10.1029/2008GC002063

Grove, T. L., Kinzler, R. J., and Bryan, W. B. (1992). "Fractionation of mid-ocean ridge basalt (MORB)," in Mantle flow and melt generation at Mid-Ocean Ridges. Editors J. P. Morgan, D. K. Blackman, and J. M. Sinton (Washington, DC: AGU Advances), 281-310.

Gualda, G. A. R., and Ghiorso, M. S. (2015). MELTS_Excel: A Microsoft Excel-based MELTS interface for research and teaching of magma properties and evolution. Geochem. Geophys. Geosyst. 16, 315-324. doi:10.1002/2014GC005545

Hart, S. R., Blusztajn, J., Dick, H. J. B., Meyer, P. S., and Muehlenbachs, K. (1999). The fingerprint of seawater circulation in a 500-meter section of ocean crust gabbros. Geochem. Cosmochim. Acta 63, 4059-4080. doi:10.1016/S00167037(99)00309-9

Hertogen, J., Emmermann, R., Robinson, P. T., and Erzinger, J. (2002). Lithology, mineralogy, and geochemistry of the lower ocean crust, ODP Hole 735B, Southwest Indian Ridge. Proc. Ocean Drill. Prog. Sci. Results 176, 75. doi:10. 2973/odp.proc.sr.176.003.2002

Holm, P. M. (2002). Data report: on the composition of the lower ocean crustmajor and trace element analyses of gabbroic rocks from Hole 735B, 500-1500 mbsf. Proc. Ocean Drill. Prog. Sci. Results 176, 1-13. doi:10.2973/odp.proc.sr. 176.020.2002

Hooft, E. E. E., Detrick, R. S., and Kent, G. M. (1997). Seismic structure and indicators of magma budget along the southern East Pacific Rise. J. Geophys. Res. Solid Earth 102 (B12), 27319-27340. doi:10.1029/97JB02349

Ildefonse, B., Blackman, D. K., John, B. E., Ohara, Y., Miller, D. J., MacLeod, C. J., et al. (2007). Oceanic core complexes and crustal accretion at slow-spreading ridges. Geology 35, 623-626. doi:10.1130/G23531A.1

Jian, H., Singh, S. C., Chen, Y. J., and Li, J. (2016). Evidence of an axial magma chamber beneath the ultraslow-spreading Southwest Indian Ridge. Geology 45, 143-146. doi:10.1130/G38356.1
John, B. E., Foster, D. A., Murphy, J. M., Cheadle, M. J., Baines, A. G., Fanning, C. M., et al. (2004). Determining the cooling history of in situ lower oceanic crustAtlantis Bank, SW Indian Ridge. Earth Planet. Sci. Lett. 222, 145-160. doi:10. 1016/j.epsl.2004.02.014

Kelemen, P. B., Koga, K., and Shimizu, N. (1997). Geochemistry of gabbro sills in the crust-mantle transition zone of the Oman ophiolite: implications for the origin of the oceanic lower crust. Earth Planet. Sci. Lett. 146, 475-488. doi:10. 1016/s0012-821x(96)00235-x

Koepke, J., Berndt, J., Feig, S. T., and Holtz, F. (2007). The formation of $\mathrm{SiO}_{2}$-rich melts within the deep oceanic crust by hydrous partial melting of gabbros. Contrib. Mineral. Petrol. 153, 67-84. doi:10.1007/s00410-006-0135-y

Koepke, J., Botcharnikov, R. E., and Natland, J. H. (2018). Crystallization of latestage MORB under varying water activities and redox conditions: implications for the formation of highly evolved lavas and oxide gabbro in the ocean crust. Lithos 323, 58-77. doi:10.1016/j.lithos.2018.10.001

Koepke, J., Feig, S., and Snow, J. (2005a). Late stage magmatic evolution of oceanic gabbros as a result of hydrous partial melting: evidence from the Ocean Drilling Program (ODP) Leg 153 drilling at the Mid-Atlantic Ridge. Geochem. Geophys. Geosyst. 6, Q02001. doi:10.1029/2004GC000805

Koepke, J., Feig, S. T., and Snow, J. (2005b). Hydrous partial melting within the lower oceanic crust. Terra. Nova. 17, 286-291. doi:10.1111/j.1365-3121.2005. 00613.x

Kvassnes, A. J. S. (2003). The evolution of oceanic gabbros: in situ and ancient examples. PhD thesis. Cambridge (MA): Massachusetts Institute of Technology and Woods Hole Oceanographic Institution.

Lambart, S., Koornneef, J. M., Millet, M.-A., Davies, G. R., Cook, M., and Lissenberg, C. J. (2019). Highly heterogeneous depleted mantle recorded in the lower oceanic crust. Nat. Geosci. 12, 482-486. doi:10.1038/s41561-019-0368-9

Leuthold, J., Lissenberg, C. J., O’Driscoll, B., Karakas, O., Falloon, T., Klimentyeva, D. N., et al. (2018). Partial melting of lower oceanic crust gabbro: constraints from poikilitic clinopyroxene primocrysts. Front. Earth Sci. 6, 15. doi:10.3389/ feart.2018.00015

Lissenberg, C. J., Bédard, J. H., and van Staal, C. R. (2004). The structure and geochemistry of the gabbro zone of the Annieopsquotch ophiolite, Newfoundland: implications for lower crustal accretion at spreading ridges. Earth Planet. Sci. Lett. 229, 105-123. doi:10.1016/j.epsl.2004.10.029

Lissenberg, C. J., and Dick, H. J. B. (2008). Melt-rock reaction in the lower oceanic crust and its implications for the genesis of mid-ocean ridge basalt. Earth Planet. Sci. Lett. 271, 311-325. doi:10.1016/j.epsl.2008.04.023

Lissenberg, C. J., and MacLeod, C. J. (2016). A reactive porous flow control on midocean ridge magmatic evolution. J. Petrol. 57, 2195-2220. doi:10.1093/ petrology/egw074

Lissenberg, C. J., MacLeod, C. J., and Bennett, E. N. (2019). Consequences of a crystal mushdominated magma plumbing system: A mid-ocean ridge perspective. Philos. Trans. A Math. Phys. Eng. Sci. 377, 20180014. doi:10.1098/rsta.2018.0014

Lissenberg, C. J., MacLeod, C. J., Howard, K. A., and Godard, M. (2013). Pervasive reactive melt migration through fast-spreading lower oceanic crust (Hess Deep, equatorial Pacific Ocean). Earth Planet. Sci. Lett. 361, 436-447. doi:10.1016/j. epsl.2012.11.012

Lissenberg, C. J., Rioux, M., Shimizu, N., Bowring, S. A., and Mevel, C. (2009). Zircon dating of oceanic crustal accretion. Science 323, 1048-1050. doi:10.1126/science.1167330

MacLeod, C. J., Dick, H. J. B., Blum, P., Abe, N., Blackman, D. K., Bowles, J. A., et al. (2017). Site U1473. Proc. Ocean Drill. Progr. 360. doi:10.14379/iodp.proc.360. 103.2017

Marjanović, M., Carbotte, S. M., Carton, H., Nedimović, M. R., Mutter, J. C., and Canales, J. P. (2014). A multi-sill magma plumbing system beneath the axis of the East Pacific Rise. Nat. Geosci. 7, 825-829. doi:10.1038/ngeo2272

McDonough, W. F., and Sun, S.-S. (1995). The composition of the earth. Chem. Geol. 120, 223-253. doi:10.1016/0009-2541(94)00140-4

Natland, J. H., and Dick, H. J. B. (2001). A brief narrative history of ODP Hole 735B. Proc. Ocean Drill. Prog. Sci. Results 176, 1-20. doi:10.2973/odp.proc.sr. 176.021 .2002

Natland, J. H., and Dick, H. J. B. (2002). Stratigraphy and composition of gabbros drilled in ODP Hole 735B, SWIR: a synthesis of geochemical data. Proc. Ocean Drill. Prog.Sci. Results 176, 1-69. doi:10.2973/odp.proc.sr.176.002. 2002

Natland, J. H., Meyer, P. S., Dick, H. J. B., and Bloomer, S. H. (1991). Magmatic oxides and sulfides in gabbroic rocks from Hole 735B and the later development 
of the liquid line of descent. Proc. Ocean Drill. Prog. Sci. Results 118, 75-111. doi:10.2973/odp.proc.sr.118.163.1991

Nguyen, D., Morishita, T., Soda, Y., Tamura, A., Ghosh, B., Harigane, Y., et al. (2018). Occurrence of felsic rocks in oceanic gabbros from IODP hole U1473A: implications for evolved melt migration in the lower oceanic crust. Minerals 8 , 583. doi: $10.3390 / \min 8120583$

Niu, Y., Gilmore, T., Mackie, S., Greig, A., and Bach, W. (2002). Mineral chemistry, whole-rock compositions, and petrogenesis of Leg 176 gabbros: data and discussion. Proc. Ocean Drill. Prog. Sci. Results 176, 1-60. doi:10.2973/odp. proc.sr.176.011.2002

Pearce, N. J. G., Perkins, W. T., Westgate, J. A., Gorton, M. P., Jackson, S. E., Neal, C. R., et al. (1997). A compilation of new and published major and trace element data for NIST SRM 610 and NIST SRM 612 glass reference materials. Geostand. Newsl. 21, 115-144. doi:10.1111/j.1751-908X.1997.tb00538.x

Rannou, E., Caroff, M., and Cordier, C. (2006). A geochemical approach to model periodically replenished magma chambers: does oscillatory supply account for the magmatic evolution of EPR $17-19^{\circ}$ S? Geochem. Cosmochim. Acta 70, 4783-4796. doi:10.1016/j.gca.2006.07.007

Reiners, P. W., Nelson, B. K., and Ghiorso, M. S. (1995). Assimilation of felsic crust by basaltic magma: thermal limits and extents of crustal contamination of mantle-derived magmas. Geology 23, 563-566. doi:10.1130/0091-7613(1995) $023<0563$ :aofcbb $>2.3 . c 0 ; 2$

Rioux, M., Cheadle, M. J., John, B. E., and Bowring, S. A. (2016). The temporal and spatial distribution of magmatism during lower crustal accretion at an ultraslow-spreading ridge: high-precision U-Pb zircon dating of ODP Holes 735B and 1105A, Atlantis Bank, Southwest Indian Ridge. Earth Planet Sci. Lett. 449, 395-406. doi:10.1016/j.epsl.2016.05.047

Robinson, P. T., Dick, H. J. B., Natland, J. H., Alt, J. C., Bach, W., Bideau, D., et al. (2000). Lower oceanic crust formed at an ultra-slow-spreading ridge: Ocean Drilling Program Hole 735B, Southwest Indian Ridge. Geol. Soc. Am. Spec. Pap. 349, 75-86. doi:10.1130/0-8137-2349-3.75

Rubin, K. H., and Sinton, J. M. (2007). Inferences on mid-ocean ridge thermal and magmatic structure from MORB compositions. Earth Planet. Sci. Lett. 260, 257-276. doi:10.1016/j.epsl.2007.05.035

Sanfilippo, A., and Tribuzio, R. (2011). Melt transport and deformation history in a nonvolcanic ophiolitic section, northern Apennines, Italy: implications for crustal accretion at slow spreading settings. Geochem. Geophys. Geosyst. 12, 1-34. doi:10.1029/2010GC003429

Sanfilippo, A., Tribuzio, R., and Tiepolo, M. (2014). Mantle-crust interactions in the oceanic lithosphere: constraints from minor and trace elements in olivine. Geochem. Cosmochim. Acta 141, 423-439. doi:10.1016/j.gca.2014.06.012

Schneider, C. A., Rasband, W. S., Eliceiri, K. W., and Instrumentation, C. (2017). NIH image to ImageJ: 25 years of image analysis. Nat. Methods 9, 671-675. doi:10.1038/nmeth.2089

Schwartz, J. J., John, B. E., Cheadle, M. J., Reiners, P. W., and Baines, A. G. (2009). Cooling history of Atlantis Bank oceanic core complex: evidence for hydrothermal activity $2.6 \mathrm{Ma}$ off axis. Geochem. Geophys. Geosyst. 10, Q08020. doi:10.1029/2009GC002466

Shipboard Scientific Party (SSP). (1989). Shipboard Scientific Party 2 HOLE 735A. Proc. Ocean Drill. Prog. Sci. Results 118, 89-222. doi:10.2973/odp.proc.ir.118. 107.1989

Singh, S. C., Crawford, W. C., Carton, H., Seher, T., Combier, V., Cannat, M., et al. (2006). Discovery of a magma chamber and faults beneath a Mid-Atlantic Ridge hydrothermal field. Nature 442, 1029-1032. doi:10.1038/nature05105
Spandler, C., and O'Neill, H. S. C. (2010). Diffusion and partition coefficients of minor and trace elements in San Carlos olivine at $1,300^{\circ} \mathrm{C}$ with some geochemical implications. Contrib. Mineral. Petrol. 159, 791-818. doi:10. 1007/s00410-009-0456-8

Suhr, G., Hellebrand, E., Johnson, K., and Brunelli, D. (2008). Stacked gabbro units and intervening mantle: a detailed look at a section of IODP Leg 305, Hole U1309D. Geochem. Geophys. Geosy. 9, Q10007. doi:10. 1029/2008GC002012

Sun, C., Graff, M., and Liang, Y. (2017). Trace element partitioning between plagioclase and silicate melt: the importance of temperature and plagioclase composition, with implications for terrestrial and lunar magmatism. Geochem. Cosmochim. Acta 206, 273-295. doi:10.1016/j.gca.2017.03.003

Sun, C., and Liang, Y. (2013). The importance of crystal chemistry on REE partitioning between mantle minerals (garnet, clinopyroxene, orthopyroxene, and olivine) and basaltic melts. Chem. Geol. 358, 23-36. doi:10.1016/j.chemgeo. 2013.08.045

Sun, C., and Liang, Y. (2014). An assessment of subsolidus re-equilibration on REE distribution among mantle minerals olivine, orthopyroxene, clinopyroxene and garnet in peridotites. Chem. Geol. 372, 80-91. doi:10.1016/j.chemgeo.2014.02.014

Sun, C., and Liang, Y. (2017). A REE-in-plagioclase-clinopyroxene thermometer for crustal rocks. Contrib. Mineral. Petrol. 172, 24. doi:10.1007/s00410-0161326-9

Tucholke, B. E., and Lin, J. (1994). A geological model for the structure of ridge segments in slow spreading ocean crust. J. Geophys. Res. 99, 11937-11958. doi:10.1029/94jb00338

van Achterbergh, E., Ryan, C. G., Jackson, S. E., and Griffin, W. L. (2001). "Data reduction software for LA-ICP-MS," in Laser ablation ICP-MS in Earth science: principles and applications. Editor P. J. Sylvester (Québec, Canada: Mineralogical Association of Canada), 239-243.

Villiger, S., Müntener, O., and Ulmer, P. (2007). Crystallization pressures of midocean ridge basalts derived from major element variations of glasses from equilibrium and fractional crystallization experiments. J. Geophys. Res. Solid Earth 112, 1-18. doi:10.1029/2006JB004342

Wood, B. J., and Blundy, J. D. (1997). A predictive model for rare earth element partitioning between clinopyroxene and anhydrous silicate melt. Contrib. Mineral. Petrol. 129, 166-181. doi:10.1007/s004100050330

Yang, A. Y., Wang, C., Liang, Y., and Lissenberg, C. J. (2019). Reaction between MORB magma and lower oceanic crust: an experimental study. Geochem. Geophys. Geosyst. 20, 4390-4407. doi:10.1029/2019GC008368

Zimmerman, M. E., Zhang, S., Kohlstedt, D. L., and Karato, S.-i. (1999). Melt distribution in mantle rocks deformed in shear. Geophys. Res. Lett. 26, 1505-1508. doi:10.1029/1999g1900259

Conflict of Interest: The authors declare that the research was conducted in the absence of any commercial or financial relationships that could be construed as a potential conflict of interest.

Copyright (C) 2020 Boulanger, France, Deans, Ferrando, Lissenberg and von der Handt. This is an open-access article distributed under the terms of the Creative Commons Attribution License (CC BY). The use, distribution or reproduction in other forums is permitted, provided the original author(s) and the copyright owner(s) are credited and that the original publication in this journal is cited, in accordance with accepted academic practice. No use, distribution or reproduction is permitted which does not comply with these terms. 